NBER WORKING PAPER SERIES

\title{
REDUCING AND PREVENTING HOMELESSNESS: A REVIEW OF THE EVIDENCE AND CHARTING A RESEARCH AGENDA
}

\author{
William N. Evans \\ David C. Philips \\ Krista J. Ruffini \\ Working Paper 26232 \\ http://www.nber.org/papers/w26232 \\ NATIONAL BUREAU OF ECONOMIC RESEARCH \\ 1050 Massachusetts Avenue \\ Cambridge, MA 02138 \\ September 2019
}

The authors would like to thank Ingrid Gould Ellen, Rachel Fyall, Ed Olsen, and Jim Sullivan for commenting on early versions of this work. Jacob Binder, Kelsey Taeckens, and Evelina Smirnitskaya at J-PAL North America provided excellent assistance cross-referencing, ensuring quality, and copy-editing. Particular thanks go to Rohit Naimpally who made vital contributions to initiate, coordinate, and inform this project. This project received financial support from J-PAL North America. Any remaining errors remain the responsibility of the authors. The views expressed herein are those of the authors and do not necessarily reflect the views of the National Bureau of Economic Research.

NBER working papers are circulated for discussion and comment purposes. They have not been peer-reviewed or been subject to the review by the NBER Board of Directors that accompanies official NBER publications.

(C) 2019 by William N. Evans, David C. Philips, and Krista J. Ruffini. All rights reserved. Short sections of text, not to exceed two paragraphs, may be quoted without explicit permission provided that full credit, including $(\odot$ notice, is given to the source. 
Reducing and Preventing Homelessness: A Review of the Evidence and Charting a Research Agenda

William N. Evans, David C. Philips, and Krista J. Ruffini

NBER Working Paper No. 26232

September 2019

JEL No. H53,I38,R21

\section{ABSTRACT}

Homelessness may be both a cause of and one of the more extreme outcomes of poverty. Governments at all levels have a variety of tools to combat homelessness, and these strategies have changed dramatically over the past quarter century. In this paper, we catalog the policy responses, the existing literature on the effectiveness of these strategies, and the major gaps that need to be addressed in future research. We focus on studies from randomized controlled trial evaluations and the best quasi-experimental designs, and discuss outstanding questions that can be addressed with these same methods.

William N. Evans

Keough-Hesburgh Professor of Economics

Department of Economics University of Notre Dame

3111 Jenkins Nanovic Halls

Notre Dame, IN 46556-7000

and NBER

wevans1@nd.edu

David C. Philips

Wilson Sheehan Lab for Economic Opportunities

Department of Economics

University of Notre Dame

3080 Jenkins Nanovic Halls

Notre Dame, IN 46556

David.Phillips.184@nd.edu
Krista J. Ruffini

University of California at Berkeley Goldman School of Public Policy

2607 Hearst Avenue

Berkeley, CA 94720

k.j.ruffini@berkeley.edu 


\section{Introduction}

In the 1870s, large numbers of able-bodied men hopped the newly built railroads that crisscrossed the country in search of economic opportunities in America's rapidly growing cities. Many of these men arrived in cities with few possessions and little money. As they struggled to find affordable nightly accommodations in their new cities, the first homelessness crisis in the modern United States was born (Kusmer 2002; DePastino 2010). The influx of immigrants to the United States in the late $19^{\text {th }}$ and early $20^{\text {th }}$ centuries (Peters 1990), the Great Depression (Schumbert 1935; Crouse 1986), the de-institutionalization of the mental health system in the 1970s (Dear and Wolch 1987), the AIDS crisis of the 1990s (Rossi 1990), veterans returning from wars in Iraq and Afghanistan (Eckholm 2007), and increased prevalence of eviction (Desmond 2016) have all changed both the number and composition of the homeless over time.

Regardless of the people afflicted or time period under consideration, homelessness may be both a cause of and one of the more extreme outcomes of poverty. As such, how governments at all levels and private philanthropy respond to homelessness is of paramount importance. In this paper, we catalog the responses to the challenge of homelessness, the existing literature on the effectiveness of these strategies, and the major gaps that need to be addressed in future research. While many forms of evidence can be informative, we prioritize studies that convincingly measure the causal impact of existing strategies on outcomes of interest. In discussing the existing work on program effectiveness, we focus heavily on highquality impact evaluations, especially those from randomized controlled trial (RCT) evaluations and the best quasi-experimental designs. Likewise, as we discuss the gaps in our current understanding, we focus on questions that can be addressed with these same methods. Throughout the paper, we restrict our review of evidence and interventions to North America in order to focus the conversation on a specific policy context while making recommendations for areas of future research with a view towards the North America-specific evidence base and ecosystem of data availability.

This review is valuable for at least four reasons. First, the human toll of homelessness is high, and understanding how best to serve this vulnerable population is crucial. On a given night, more than 500,000 people experience homelessness, and 1.42 million pass through shelters in a given year (Solari et al. 2016). 
These numbers have mostly decreased since national measurement began in earnest: between 2012 and 2016 homeless counts in the point-in-time estimates fell by 11.5 percent. However, these numbers have drifted upwards in the most recent counts, driven by large increases in cities such as New York, Los Angeles, Seattle, and San Francisco. In contrast, using a broader definition of homelessness, the Common Core of Data database indicates that the number of students experiencing homelessness has increased each year since 2009, reaching over 1.3 million students during the 2015-16 school year (Snyder et al. 2018).

Second, the financial resources devoted to combatting homelessness are substantial. Direct federal funding for local organizations to combat homelessness totals about $\$ 6.1$ billion annually (USICH 2018). This is, however, only a fraction of the dollars devoted to this issue. State and local governments, as well as private dollars, all contribute to fighting homelessness. While there is no systematic data on the amount of nonfederal sources of funds for the nation as a whole, anecdotal data suggests these numbers are large. For example, New York City spends a total of $\$ 1.8$ billion on programs for people experiencing homelessness and only about one third comes from federal dollars (Johnson and Levin 2018).

Third, the organization of services for the homeless has evolved considerably over the past thirty years. Local resources have become more coordinated. Historically, a patchwork of local public agencies and private organizations have spearheaded the fight against homelessness. Since 1995, the United States Department of Housing and Urban Development (HUD) has required each community to submit a single comprehensive Continuum of Care $(\mathrm{CoC})$ application with the intent to stimulate community-wide planning and program coordination (HUD 2012). ${ }^{1}$ To facilitate the distribution of federal dollars to the areas with the highest need, HUD has required CoCs to conduct a point-in-time estimate of the homeless population since 2007, providing annual estimates of the homeless population under a common definition. Along the same timeline, many communities have moved toward "coordinated entry" systems. While homelessness programs

${ }^{1} \mathrm{~A}$ CoCs is a regional or local organization that coordinates homelessness prevention and mitigation programs for individuals and families experiencing homelessness. A CoC can be as large as a state (such as MT-500) or serve a small population (such as MD-510 for Garret County, with a population of only 29,500). In 2007, there were $461 \mathrm{CoCs}$ in the United States and its territories. By 2017, this number had fallen to 397. 
remain spread across many organizations, communities now frequently funnel clients through a common portal that aims to direct those with housing needs to those with appropriate resources.

Finally, the types of services provided have fundamentally transformed over time. Twenty years ago, much of the resources centered on local homeless shelters. These shelters were part of a linear treatment program where a person experiencing homelessness was required to participate in and graduate from shortterm residential and treatment programs before obtaining permanent housing. In these programs, residents had to satisfy preconditions, such as sobriety, before they could move into a permanent residence. In the late 1990s and early 2000s, new voices advocated for a model that prioritizes immediate housing. This approach is guided by the belief that providing basic necessities such as housing and food are preconditions to solving other problems like finding employment or dealing with substance use issues. Evidence was a fundamental part of this new model from the beginning. The Pathways to Housing demonstration project by Tsemberis and Eisenberg (2000) provided evidence that a "Housing First" model applied to permanent, supportive housing could effectively house chronically homeless people. A successful randomized evaluation of Housing First programs for veterans (Rosenheck et al. 2003) led to a massive expansion of the US Department of Housing and Urban Development Veterans Administration Supportive Housing (HUD-VASH) program which has distributed more than 97,500 vouchers to veterans experiencing homelessness since 2008 . These initial experiences have made the Housing First model the preferred treatment option for people who are chronically homeless and special populations, including veterans and those facing mental health and substance use issues. The same rationale has expanded the general approach of providing immediate housing to non-permanent forms of assistance. For example, rapid re-housing programs, which provide immediate temporary subsidies for market housing, have replaced many traditional programs for people experiencing somewhat less chronic situations of homelessness. These large changes in the organization and content of homelessness services suggest it is time to take stock of what we know and do not know about the effectiveness of current programs.

In the next section, we outline how homelessness is defined across federal agencies, discuss those groups most at risk of becoming homeless, and examine how the patterns of homelessness have changed 
over time. In Section III, we outline current methods for reducing and preventing homelessness, and in Section IV we review high-quality research measuring the effectiveness of such methods. In Section V, we discuss some of what we believe to be key outstanding research questions.

\section{Measuring homelessness and the extent of the problem \\ A. Defining homelessness}

Measuring the number of people who are experiencing homelessness requires a definition of homelessness. Unfortunately, there are a variety of definitions across government programs and agencies that complicate measurement. School-aged children "who lack a fixed, regular, and adequate nighttime residence" are eligible for educational benefits for homeless children under the McKinney-Vento Homeless Assistance Act. The definition includes children living in shelters and those living in "public or private places not ... ordinarily used as a regular sleeping accommodation for human beings" as well as children "who are sharing the housing of others" or living in "motels, hotels, trailer parks, or camping grounds due to the lack of alternative adequate accommodations." While the McKinney-Vento definition includes people whom many would consider homeless — those living in shelters, in cars, or on park benches—it also controversially includes children sharing housing of others, or doubled-up. As we outline below, the doubled-up numbers are enormous. Currently, this group is not eligible for federal HUD homelessness assistance. The Homeless Emergency Assistance and Rapid Transition to Housing (HEARTH) Act, ${ }^{2}$ passed in 2009, defines those eligible for HUD assistance if they meet one of four definitions of homelessness: a) Living in a place that is not meant for habitation, which includes emergency shelters and transitional housing; b) people who are expected to lose their residence within fourteen days, including people living in doubled-up arrangements; c) families with children that are unstably housed; d) people fleeing domestic violence. Under this definition, those doubled-up are only eligible for funds if they are about to become homeless. Proposed legislation such as H.R. 32 in $2012^{3}$ and the Homeless Children and Youth Act (HCYA) of 2017 in the Senate sought to $^{2}$

\footnotetext{
2 H.B. 1877, 111 th U.S. Congress, available at: https://www.congress.gov/bill/111th-congress/house-bill/1877

${ }^{3}$ H.R. 32, $112^{\text {th }}$ U.S. Congress, available at: https://www.congress.gov/bill/112th-congress/house-bill/32

${ }^{4}$ S.B. 611, 115th U.S. Congress, available at: https://www.congress.gov/bill/115th-congress/senate-bill/611/text
} 
expand the HEARTH definition to include those doubled-up. Although HCYA was supported by over 400 homeless advocacy groups (Bardine 2015), the bill was met with some resistance from some national organizations such as the Corporation for Supportive Housing and the National Alliance to End Homelessness (NAEH 2015). These groups argued that the bill greatly expands the number of homeless without a corresponding change in funding and hence would divert resources from more challenging cases of homelessness. As we outline below, whether one includes doubled-up families in the homeless counts changes the number and trends in homelessness dramatically.

\section{B. Overall magnitude and risk factors}

The primary data on homeless incidence come from the annual point in time (PIT) count conducted on a single night in January. The count was started in sixty municipalities in 1983 and a nationwide methodology was adopted in 2007. Nationwide, the counts are organized by a local CoC. The sheltered homeless are counted on an annual basis and unsheltered counts are required at least once every two years, with odd calendar years being required years. PIT counts must be conducted during the last ten calendar days in January. Sheltered locations include homeless shelters, domestic violence shelters, hotels and motels where the rent is paid for by a public or private agency because the person is experiencing homelessness, safe havens and transitional housing. Those living in doubled-up arrangements are not included.

In column 1 of Table 1, we report the rate of homelessness per 100,000 people in 2017 from the PIT estimates. ${ }^{5}$ In subsequent rows, we report the rate for some specific demographic subgroups. In column 2, we report the share of the population from a particular group, and in column 3 we report the share of those experiencing homelessness in that group. The numbers from column 3 are taken from the 2013-2017 American Community Survey (ACS) or from other sources as indicated in the table. In the final column, we report the risk ratio, which for a dummy variable $\mathrm{x}$ is $\operatorname{Pr}[$ homeless $\mid x=1] / \operatorname{Pr}[$ homeless $\mid x=0]$. A value of 2 means that having $x=1$ doubles your chance of homelessness. The rate for males and females will simply

\footnotetext{
5 These numbers are for the fifty states and the District of Columbia.
} 
be inverses of each other and the rate for African Americans is the value compared to non-African Americans.

Reading down the rows of the table, males comprise 60 percent of people experiencing homelessness and have a 60 percent higher chance of homelessness than females. Hispanics are 25 percent more likely to be homeless than non-Hispanics. Across racial groups, Asians and Whites are far less likely to be experiencing homelessness as people not in those groups. Native American/Alaska Natives, African Americans, and Pacific Islanders are 4, 5, and 7.5 times as likely to be experiencing homelessness as people not in the respective group. African Americans are only 13 percent of the population but are 41 percent of those who are experiencing homelessness. There is little difference by the age groupings but a shortcoming of the aggregate PIT data is that it has a broad age range for the oldest age group.

The PIT estimates report homeless counts for families with children under 18 and unaccompanied children under 18. Pooling these groups and comparing to all others, families with children are less likely to experience homelessness than single individuals or those in families without children.

In the next set of rows, we report the numbers for special groups. In many of these situations, we use estimates from sources other than the ACS to generate the denominator. In each of these cases, the group with special needs has much higher rates of homelessness. Veterans are 25 percent more likely to be homeless than non-veterans. The four other groups are severely over-represented among those experiencing homelessness. The National Institutes of Mental Health estimates that among adults, 3.3 percent of the population is experiencing severe mental illness. This group, however, represents one-fifth of all people experiencing homelessness, with a risk ratio approaching 8. Chronic substance users have a risk ratio of three and are one-sixth of the homeless population. In the population, three-tenths of 1 percent are HIV-positive, but one in thirteen people experiencing homelessness are, leading to a risk ratio of 25. Finally, those fleeing domestic violence are one-twentieth of the population but represent one-sixth of all people experiencing homelessness, implying a risk ratio in excess of $3 .^{6}$

\footnotetext{
${ }^{6}$ The denominator in this estimate is most likely in error. The PIT count includes children and adults that are victims of domestic violence. The best estimate we could get on domestic violence incidence rates are from the National Intimate Partner and Sexual Violence Survey from 2010. These estimates indicate that 5.9 percent of females and 5 percent of
} 
In the last group of estimates, we generate risk ratios based on the type of area served by the CoC. In many cases, local areas are served by multiple CoCs (e.g., Los Angeles County has four CoCs) while some CoCs have overlapping jurisdictions (e.g., CoCs near Chicago and Boston). Evans et al. (2019) group CoCs by service area and we use their mapping of CoCs to generate these numbers. Homelessness is much more prevalent in large metro areas. The risk ratio for CoCs in the top ten metro areas (by population) is 2.5 while the number falls to 1.4 for the 15 largest metro areas. In other metro areas and non-metro areas, the risk ratio is much less than 1 . What we do not know is whether there is a difference in the accuracy of the PIT estimates based on city size. If the non-sheltered homeless are more difficult to count in less urban areas, the risk ratio for these areas could be vastly understated.

\section{Trends in point-in-time counts}

Figure 1 shows the annual PIT estimates from 2007 to 2018. The number of people experiencing homelessness declined 15 percent from 2007 to 2016 with most of the decline for unsheltered homelessness, which declined by 31 percent over the same period. Since 2016, however, the unsheltered homeless counts have increased by 10 percent. Measured as a rate (number experiencing homelessness per 100,000), homelessness has declined 21 percent since 2007. The decline in homelessness has been across a broad range of groups. In Figure 2, we report the time series numbers for a number of different subgroups from 2007 to 2018. Homelessness among veterans peaked in 2010 and fell 50 percent over the next eight years.

Homelessness among non-veterans fell by about 9 percent over the same period and among the chronically homeless by almost 20 percent over the entire period. Homelessness among people in families fell by 25 percent from its 2010 peak, but only 10 percent for individuals from its 2007 peak.

Not all areas have experienced a decline in homelessness. The trends in New York City (CoC NY600) and Los Angeles County ${ }^{7}$ have been particularly different from the rest of the country. In Figure 3, the

males aged 18 or older nationwide experience rape, domestic violence or stalking in the past 12 months. We use these numbers to generate a rate for the nation as a whole. We suspect that the majority of those experiencing homelessness in this case are women and children and generating a rate for this group would most likely produce a much higher risk ratio.

${ }^{7}$ Here we pool data for the four CoCs in Los Angeles County to represent the entire county. 
solid lines report homelessness rates (x 100,000) for Los Angeles County and New York City (right vertical axis). Note that since 2012, these rates have increased by 57 and 31 percent, respectively. The impact of these two cities is dramatic for state and national estimates. While these cities represent less than 6 percent of the nation's population, they accounted for a quarter of the homeless population in 2017 . The dotted lines with the same shade represent the rest of the states of California and New York (left vertical axis), respectively. Note that the homelessness rates for the rest of California have fallen by 13 percent over this same period (although the rate increased between 2016 and 2017) while the rate in the rest of New York has been unchanged. Nationwide, rates have fallen 14 percent since 2012 and national rates excluding Los Angeles County and New York City (dashed black line, left axis) have fallen 24 percent. It is tempting to suggest this is simply a "big city" phenomenon, as other large cities have experienced big increases in the homelessness rate since 2012 including Seattle (21 percent), San Francisco (10 percent), Berkeley/Oakland (23 percent), and Sacramento (24 percent). This pattern, however, is not universal: some large and growing cities have experienced massive declines in homelessness including Phoenix (-20 percent), Houston (-54 percent), Dallas/Fort Worth (-46 percent), San Diego (-14 percent), and Atlanta/Fulton County (-40 percent). What is happening in New York and Los Angeles is an open question. These two cities have the highest numbers of people experiencing homelessness and the shocking increases in homelessness rates for these areas can drive national estimates. The causes appear to be local. The Los Angeles CoC (CA-600) has experienced a 75 percent increase in homeless counts, but in the other three CoCs in Los Angeles County (Glendale, Long Beach and Pasadena), homeless counts fell 40 percent. Likewise, there are two CoCs in the state of New York (Westchester and Nassau) and four in New Jersey (Bergen, Newark, New Brunswick, and Monmouth) that border the New York City CoC, and homeless counts in these CoCs were roughly the same in 2017 as they were in 2012. It is possible that the explanation is not the same for both cities. In New York City, 62 percent of the increase is from families with children under 18. In Los Angeles, this group only represents about 7 percent of the increase. In New York City 97 percent of the increase is in the sheltered homeless population, whereas 99 percent of the increase in Los Angeles is in the unsheltered population. 
Rent levels cannot explain the dramatic increase in New York and Los Angeles, but can explain some of the differences in homelessness rates across CoCs. Figure 4 shows the relationship between median rent for a one-bedroom apartment and homelessness rates across CoCs in 2017. There is a clear positive relationship between rent levels and homelessness; however, this relationship is far from perfect $\left(R^{2}=0.16\right)$. Los Angeles County and New York City appear as the clear, large outliers above the regression line, with rent levels predicting some but not most of their very high rates of homelessness. Figure 5 shows the same graph in changes between 2010 and 2017. The positive relationship between rent and homelessness weakens $\left(R^{2}=\right.$ 0.03) when considering changes. While rent levels can explain some differences in homelessness rates across CoCs, changes in rent levels hold little predictive power.

\section{Challenges to measurement}

The PIT estimates are subject to many limitations. First, the estimate is at a point in time. The number of people experiencing homelessness over a longer interval will be larger by construction. The Homeless Management Information System (HMIS) is a nationwide network of local IT systems that collect client-level data for people entering sheltered services. These systems are organized at the CoC level and most homeless shelters across the country are part of the HMIS system. In 2016, HMIS produced an un-duplicated count of 1.42 million people in the shelter system (Solari et al. 2016). The comparable estimate of sheltered people from the PIT estimate was 373,571. Along this dimension, the point-in-time component of the estimate understates annual exposure by a factor of almost four. ${ }^{8}$

Given the difficulty in finding people who are unsheltered, the PIT estimates will also systematically understate the size of this group. The PIT procedures are designed to locate as many of this group as possible by visiting where people experiencing homelessness are known to congregate. The procedure will miss people in more obscure places and will miss those not wanting to be counted. To obtain an estimate of the undercount of the unsheltered, some have used a plant-recapture technique where paid plants are sent to

\footnotetext{
${ }^{8}$ HMIS, though, may overstate exposure to the extent that migrants across CoC borders and de-identified individuals (e.g. minors) enter HMIS more than once but cannot be de-duplicated.
} 
locations where enumerators are known to visit and subsequently report back as to whether they were surveyed (Laska and Meisner 1993; Shaw et al. 1996; Hopper et al. 2008; McCandless et al. 2016). Studies by Laska and Meisner (1993) and Hopper et al. (2008) done decades apart in New York City both found PIT estimates understate the rate of unsheltered homelessness by about $40-50$ percent.

As mentioned earlier, the PIT estimates do not include those doubled-up. Doubling-up is very common, particularly among low-income families, who might double-up in order to avoid material hardship (Mykyta and Pilkauskas 2016). Mykyta and Macartney (2011) use data from the Current Population Survey and estimate that in March 2010, 24.1 percent of households were doubled-up. Pilkauskas, Garfinkle and McLanahan (2014) note that among participants in Fragile Families and Child Wellbeing Study, 50 percent had lived doubled-up as an adult. Participants in the Family Options Study usual care group were more than three times more likely to live doubled-up than have stayed in an emergency shelter in the previous six months (Gubits et al. 2016). While the exact extent is hard to measure, the data above indicate that doubling up is quite common.

The best estimates of the extent of doubling up are reported by the National Center for Education Statistics (NCES). Since 1987, schools have been required to report to the NCES the number of students experiencing homelessness as defined by McKinney-Vento. These data are aggregated over a school year and hence are not a point-in-time estimate but, rather, are estimates of who experienced homelessness over the previous year. Aggregate counts of these numbers are available from the 2009-10 school year through 201617 for all students in public PK-12 schools. The NCES reports the number of students in four categories: sheltered and unsheltered homeless, which are comparable to the definitions used by the PITs, those living in hotels/motels, and those doubled-up. While the PIT includes those in hotels/motels if a family's stay is paid for by a third party, the NCES definition is much broader.

In Table 2, we report a comparison of estimates of those experiencing homelessness by category from the 2014-15 NCES and the 2015 PIT. In the top half of the table we report the direct comparisons of sheltered and unsheltered homelessness between the two sources. The numbers in parentheses are rates per 100,000. The NCES includes everyone in public PK-12 schools. The numbers for the PIT are all children 
under the age of 18, including those too young for school. Dividing the population under 18 by the number of students in public school generate a ratio of 1.46, so if homelessness rates are uniform by age, dividing the PIT estimates by 1.46 should make them comparable to the NCES numbers. In the NCES estimates there were 180,302 individuals experiencing homelessness in shelters and the corresponding number for the PIT is 111,692. Dividing this by 1.46 generates 76,501 . The ratio of the full-year to the PIT estimate is then 2.4, which is smaller than the factor of four listed above comparing the HMIS full-year unduplicated numbers compared to the PIT estimates. In the second half of the table, we report counts from non-PIT categories. The motels/hotels number is comparable in magnitude to the scaled PIT estimate for the sheltered homeless. More importantly, there are over a million children doubled-up. Overall, the number of children experiencing homelessness from the PIT is one-tenth the number according to the NCES.

The numbers in Figures $1-2$ tell an encouraging story that homelessness has been declining in most of the country over the past decade. Unfortunately, including doubled-up housing situations in homeless counts changes numbers dramatically not only in the cross-section, but in the time series as well. In Figure 6, we report time series of homeless counts from the NCES for the sheltered, doubled-up and total homeless alongside sheltered PIT counts. ${ }^{9}$ The sheltered count from the PIT shows a decline that is fairly pronounced over the final three years. In contrast, the NCES numbers are increasing throughout the time period. Total homelessness in the NCES data increased by 55 percent throughout the period with 75 percent of the increase among those doubled-up.

\section{E. Costs of homelessness}

In addition to affecting many people, homelessness generates very large private and public costs.

Most obviously, people lose access to any surplus value of their prior housing over and above the cost of that housing. Unfortunately, many such private benefits are difficult to measure. The public cost of housing someone who is experiencing homelessness is more straightforward to measure. Spellman et al. (2010) found

\footnotetext{
${ }^{9}$ Unfortunately, the HUD exchange does not report homeless children for all years so the most comparable series we can report are sheltered homeless families with children. In 2014, children were 59 percent of this group. For school year 2009-2010 we report the PIT estimates from 2010.
} 
that the average cost of housing a newly homeless family or individual for the duration of them experiencing homelessness is upwards of $\$ 2,000$.

The other public costs of homelessness potentially swamp the direct cost of housing. Since the pioneering work of Culhane et al. (2002), a number of authors have attempted to estimate the public costs of homelessness at the local level. One of the more extensive of these case studies was from Santa Clara County, California where administrative data on homelessness was linked to records for various other public services (Flaming et al. 2015). The cost of all public services averaged $\$ 83,000$ per person experiencing homelessness per year. Of that total, 53 percent was related to healthcare and 34 percent to criminal justice. Only 13 percent came from all other social welfare services, including homelessness services but also foster care, food, and cash assistance. This specific case study matches what is known from other contexts. As noted above, people who are experiencing homelessness are more likely to experience health issues such as mental illness, substance use, and HIV. Barrow et al. (1999) found two to three times greater mortality rates among people in New York City shelters compared to the general population of New York City. People who are experiencing homelessness also have more contact with the criminal justice system. Cronley et al. (2015) found that people with a history of homelessness are 60 percent more likely to commit violent crime and 30 percent more likely to commit property crime, after controlling for observable differences. Snow et al. (1989) found that men experiencing homelessness in Austin are more likely to be arrested than the general population of males. Most of this difference is due to public intoxication and theft, which could indicate differences in treatment by police rather than actual differences in criminality. Desmond (2016) argues that eviction causes poverty by hindering employment, and Desmond and Gershenson (2016) found that Milwaukee renters are 11 to 22 percent more likely to lose a job after a forced move compared to a matched comparison group. People experiencing housing instability clearly have worse health, criminal justice, and employment outcomes.

Two caveats regarding the cost of homelessness are important. First, the correlation of homelessness with poor outcomes does not necessarily imply homelessness creates these costs. For example, recent studies of eviction court in Chicago (Humphries et al. 2018) and New York (Collinson and Reed 2018) demonstrate 
that evictions follow dramatic dips in creditworthiness and financial stability, context which could be missed in typical surveys. Second, the distributions of the various public costs of homelessness can be skewed. In Spellman et al. (2010), the costliest 10 percent of people incur up to 83 percent of the total costs of shelter during homelessness. In Flaming et al. (2015), individuals with costs in the top 5 percent of the public costs incur 47 percent of all costs. Hence, whether a program targets the costliest cases matters significantly for the mean costs reported above.

\section{Strategies and resources for reducing homelessness \\ A. Interventions targeted at homelessness}

The McKinney-Vento Homeless Assistance Act of 1987 was the first large-scale federal effort providing dedicated funding to programs and services to families and individuals experiencing homelessness. McKinney-Vento provided federal funds to public and private local housing agencies to support a variety of programs. Historically, the local system to combat homelessness was very fragmented with little coordination. The grants supported by McKinney-Vento went to a variety of public agencies and local charities. In 1995, HUD began requiring communities to submit a single application for McKinney-Vento grants to streamline the application process, encourage coordination of services at the local level, and help promote the CoC model introduced above. For example, All Chicago is the coordinating agency for the Chicago $\mathrm{CoC}$ and their web page lists 265 partner agencies. Some agencies specialize in providing services to some groups (e.g., veterans, families, victims of domestic abuse, etc.), while some specialize in specific types of services (e.g., emergency financial assistance, shelter, supportive housing, etc.).

Thus, we start with the menu of policy and program options available at a local level. Since the passage of McKinney-Vento, localities have implemented several approaches to reduce or prevent homelessness. In this section, we discuss each of these interventions, including their modern history and recent changes. We organize these interventions by their target population, starting with homelessness prevention and proceeding to interventions for people who are already experiencing homelessness: transitional housing, permanent supportive housing, and re-housing subsidies. 


\section{Prevention}

Homeless prevention programs aim to provide time-sensitive, short-term assistance to at-risk households before families actually lose housing. Prevention can involve landlord/household mediation, short-term financial assistance, case management, or legal assistance.

The most widely-available form of assistance is a hotline that residents can call for financial assistance if they are at risk of losing their residence or having their utilities discontinued. In most areas, the system is coordinated by United Way and families call or text 2-1-1 to connect to the service. The first system that was available 24/7 started in Atlanta in 1997, and coverage increased after 2000 when the Federal Communications Commission (FCC) dedicated the 2-1-1 dialing arrangement for information and referral services (United Way of Metro Atlanta 2018; FCC 2000). As of 2018, about 94 percent of the population has access to 2-1-1, and each year, these hotlines receive approximately 13 million requests for assistance (About 2-1-1 2018). For example, in Chicago a typical household assisted from a 2-1-1 call receives one month of rent, paid to the landlord (Palmer et al. 2019).

Legal representation in eviction court has recently gained increased attention as a homelessness prevention tool. This is driven in large part by Desmond (2016)'s Pulitzer Prize winning book Evicted. The ethnographic work in the book argues that an eviction is the first in a line of events that can generate financial wounds from which many families can never recover. Households facing eviction are at risk for homelessness, particularly as tenants are less likely than landlords to have full legal counsel. In eviction court proceedings, 90 percent of landlords were represented by an attorney, while less than 10 percent of tenants have representation (Desmond 2012). ${ }^{10}$ Even when legal assistance is offered, it is commonly "unbundled" aid that takes the form of how-to clinics and informational assistance, rather than a full attorney-client relationship. These forms of unbundled assistance have become more common since the 1970s, and currently every state operates at least one program that provides limited legal assistance (Greiner et al. 2013). Legal aid

\footnotetext{
${ }^{10}$ Engler (2010) summarizes existing studies that find between 0 to 20 percent of tenants had legal representation, compared to at least $80-90$ percent of landlords.
} 
groups will often supplement such assistance with full services targeted at a very narrow group of tenants

with clear legal cases likely to win. More recently, some jurisdictions have taken steps to significantly increase the share of tenants with representation. For example, in 2017, New York City enacted Local Law 136, which provides full legal assistance to low-income tenants facing housing court proceedings (NYC Local Law 2017/136), and in 2018, San Francisco passed Proposition F, which guarantees full legal assistance for all households facing eviction, regardless of income. Although full representation is not guaranteed in other jurisdictions, cities including Denver, CO; Washington, DC; and Philadelphia, PA have increased funding for legal aid services (Wiltz 2017).

Prevention efforts face a challenge in identifying which individuals may become homeless in the absence of intervention. In the work of Evans et al. (2016), only 2 percent of families who request and are denied financial assistance to prevent homelessness actually enter shelter within six months. Even in New York City, where a right to shelter makes emergency shelter use more common, only 12.8 percent of families applying for services enter a shelter within three years (Shinn et al. 2013). As a result, a trade-off exists between intervening early when housing instability is less severe and targeting interventions to those at greatest risk.

\section{Transitional housing versus Housing First approaches}

Until recently, families and individuals experiencing homelessness accessed housing assistance through a continuum model. Emergency shelters served as the first port of entry and provided families and individuals with temporary housing without rent or lease agreements until residents were able to find more permanent housing. Frequently, emergency shelter provides supportive services aimed at getting residents "housing ready" and able to procure private-market housing.

After accessing emergency shelter, families and individuals could move to project-based transitional housing, or just "transitional housing." Like emergency shelter, transitional housing provides temporary assistance, usually for no longer than 24 months. In addition to providing shelter, transitional housing provides supportive services. These services may be designed to help tenants find and secure permanent 
housing or address other issues. Continued receipt of transitional housing may be contingent on households satisfying certain requirements, such as sobriety, employment, or participation in mental health treatment, which embeds a trade-off in the continuum model between providing housing and enforcing such conditions. Many communities have shifted some resources for chronically homeless individuals away from the continuum model toward a Housing First strategy that provides households experiencing homelessness with immediate housing with few to no preconditions or contingencies. The guiding rationale for the Housing First approach is that homelessness is detrimental to families and individual well-being, and obstacles to economic self-sufficiency or family well-being are more easily addressed if a family is in permanent, stable housing (Burt et al. 2016). ${ }^{11}$

The movement to providing individuals and families experiencing homelessness with immediate housing has come with additional federal dollars. The original McKinney-Vento legislation provided support under the Supportive Housing Program. Rapid re-housing programs were not explicitly included as an eligible use of federal McKinney-Vento funds until the 2009 HEARTH Act whose passage dramatically increased the federal dollars spent on these programs. At the same time, the creation of programs such as the Homeless Prevention and Rapid Re-housing Program (HPRP) and Supportive Services for Veteran Families (SSVF) indicated a further shifting in focus towards Housing First approaches.

\section{Supportive housing}

Supportive housing is a housing first strategy that helps individuals with mental or substance use disorders who are experiencing homelessness find long-term, affordable, and independent housing. Cities and local service providers began to implement supportive housing programs in the late 1980s and early 1990s.

\footnotetext{
11 "Housing First" originally referred to programs offering immediate, permanent housing opportunities. In recent years, this term has also been used to refer to rapid re-housing programs that provide immediate, but temporary, rental assistance and subsidies. As discussed in National Academy of Sciences (2018) and HUD (2014), there is some disagreement over whether rapid re-housing programs are considered Housing First approaches. Following the National Academy of Sciences and HUD, this overview categorizes rapid re-housing as a program model that follows the Housing First approach of providing immediate housing to families and individuals experiencing homelessness, without requiring participation in other programs or adhering to behavioral requirements, but that differs from traditional permanent supportive housing and Housing First approaches by offering time-limited (rather than permanent or longterm) assistance.
} 
These early endeavors included Beyond Housing in Los Angeles, Pathways in New York City, and Rapid Exit in Hennepin County, Minnesota. These early interventions emphasized a "consumer-based" model, and aimed to serve clients who were ineligible for other interventions due to lack of engagement in supportive services (Tsemberis 1999). In most programs, clients pay no more than 30 percent of their monthly income in rent and have access to ongoing case management that is designed to preserve tenancy. Wrap-around supportive services, including mental health programming and substance use treatment, may be provided onor off-site. Crucially, and unlike many traditional approaches, these programs provided housing without requirements of sobriety, employment, or other participation in program supportive services. Over the past twenty years, the scope of supportive housing programs has broadened to include populations other than chronically homeless individuals. In 2017, approximately half of supportive housing beds targeted persons in families (Henry et al. 2017). Supportive housing programs that do not have time limits on receipt are referred to as "permanent supportive housing" or PSH.

By far the largest expansion of the housing first strategy came with the expansion of the HUDVASH program. Created in the early 1990s as a demonstration project and using a PSH approach, the HUDVASH program subsidizes veteran housing through housing choice vouchers (HCV) and offers supplementary case management services. The local public housing authority (PHA) distributes the vouchers to veterans, oversees how the voucher is used and whether it meets program standards, and assists veterans with rent negotiations, inspections, and other housing-related tasks. Veterans are responsible for paying rent of up to 30 percent of their income while the voucher covers the rest (Montgomery and Cusack 2017). A Veteran Affairs Medical Center (VAMC) coordinates with the local PHA to screen veterans and provides case management and clinical services. To be eligible for HUD-VASH, veterans must be homeless as defined by the McKinney-Vento Homeless Assistance Act, eligible for VA health care, agree to intensive case management, and have no prior convictions for arson or sex offenses (Crone 2017). Evidence from random assignment experiments showed that the HUD-VASH system reduced homelessness and improved outcomes. Since 2008, the program has awarded resources for about 10,000 PSH vouchers annually. The 
program was a cornerstone of the of the Obama Administration's 2009 announced goal to end Veterans' homelessness within five years.

\section{Rapid re-bousing}

Rapid re-housing $(\mathrm{RRH})$ is a model that follows the Housing First approach in offering time-limited rental assistance and services to families and individuals experiencing homelessness (National Academy of Sciences 2018). While both supportive housing and rapid re-housing provide housing emphasizing client selfdetermination — that is, without requiring that households satisfy certain requirements, such as maintaining sobriety or employment - these programs differ in the duration of assistance. Supportive housing programs offer permanent housing and tend to serve households with relatively high needs, while rapid re-housing provides short-term assistance that is usually targeted to households with more moderate barriers to housing stability (Burt et al. 2016).

Subsidized housing in RRH programs may be market housing (scattered site) or owned by the program administrator (project-based). Families may also receive other services, including move-in assistance, case management, or housing search and placement assistance, and there is substantial variation in the types and intensity of services offered. For example, for housing search assistance, some programs take an indirect approach and provide clients with a website or listing of potential properties, while others have housing specialist staff who take a more direct role in helping recipients connect with landlords or directly manage properties that may be available to clients (Burt et al. 2016).

Early rapid re-housing programs began with local service providers and state funds, including Hennepin County, MN; Boston, MA; Columbus, OH; and Los Angeles, CA in the late 1980s and early 1990s. In many cases, excess demand for emergency shelter beds prompted local providers to change their delivery model to focus on quickly re-housing clients who were experiencing short-term crises in permanent housing, rather than having these residents reside in emergency shelter beds and participate in activities designed to make families housing ready (NAEH 2014; Cunningham et al. 2015). 


\section{5. $\quad$ Trends in resources}

Part of the decline in the national homeless counts outlined in Figures 1 and 2 above is from additional resources devoted towards homelessness. In the top two lines of Figure 7, we report the number of beds for shelter (x 1,000), PSH, transitional housing, VASH, and RRH from 2007 and 2017. This data is from the companion to the PIT survey called the Housing Inventory Count (HIC) that provides point-in-time counts of homelessness resources. Between 2007 and 2017, overall resources have increased, with the total number of beds rising from 611,292 to 899,059 (47 percent increase). Emergency shelter beds have increased from 211,451 to 277,537—a 31 percent increase. Figure 7 also displays the displacement of transitional housing in favor of Housing First approaches. While the number of transitional housing beds has fallen by about 43 percent—211,205 to 120,249 (Henry et al. 2017)—PSH beds have almost doubled, increasing from about 189,000 to 354,000. RRH has added 109,000 beds over the past seven years (HUD 2018b). Much of this increase has been from federal efforts to expand the use of Housing First as a tool to fight homelessness. Nearly half of the increase in PSH units is through the HUD-VASH program. Through 2018, about 97,500 vouchers have been awarded through that program.

\section{B. Broader low-income housing subsidies}

Programs that provide subsidized housing to lower-income families and individuals are not targeted to those in or at risk of homelessness but might directly reduce homelessness. Unlike other forms of federal assistance such as Temporary Assistance for Needy Families (TANF) and the Supplemental Nutrition Assistance Program (SNAP), these housing programs are not entitlements and hence, not all eligible applicants receive benefits. The Congressional Budget Office (2015) estimated that about 25 percent of eligible households received federal housing assistance.

Modern large-scale federal funding for public housing and subsidized housing dates to the United States Housing Act of 1937 (Wagner-Steagall Act). Local housing authorities provide government-owned public housing units to low-income families. Tenants contribute no more than 30 percent of their income towards rent. In addition, residents must have income below 80 percent of area median income (AMI), and at 
least 40 percent of residents must have income at or below 30 percent AMI (McCarty et al. 2014). From the beginning, the federal government provided funding, but implementation and operating procedures were devolved to local housing authorities.

The number of public housing units has fallen since the 1990s. Due to concerns about the quality of public housing and the concentration of poverty, the HOPE VI program in 1993 and the Choice Neighborhoods Initiative in 2010 called to replace dilapidated public housing units with new developments (Cisneros and Engdahl 2009). The number of units demolished under these programs exceeded the number of units built so the total public housing stock decreased about 10.5 percent between 1993 and 2016 (Kingsley 2017). The 2012 Rental Assistance Demonstration Program, which allowed PHAs to convert up to 185,000 public housing units to project-based Section 8 contracts, further reduced the public housing stock (Econometrica, Inc. 2016; JCHS 2018). In 2017, approximately 2.1 million people in 1.0 million households lived in public housing, down from about 1.2 million households in 1998 (HUD, 2018c).

While the number of public housing units has fallen, the number of housing vouchers for subsidized private housing has increased. Federal subsidies for private-market housing date to at least the 1960s, and the modern Housing Choice Voucher (HCV, or Section 8) program was codified in the 1974 Community Development Act. Like public housing, recipient households must satisfy income requirements: all tenants must have gross income (after deductions) no greater than 50 percent AMI, and 75 percent of vouchers are reserved for households with income at or below 30 percent AMI (HUD 2018a). Unlike public housing, where tenants must reside in a given project, HCV is not tied to a particular unit or landlord: HCV recipients typically pay 30 percent of their income towards rent, and the remaining rent (subject to some limits) is paid to private landlords by the federal government. In 2017, approximately 5.3 million people in 2.2 million households received a HCV, up from about 1.4 million households in 1998 (HUD 2018c).

While programs like public housing and HCV subsidize the demand side of the market, the LowIncome Housing Tax Credit (LIHTC) subsidizes the supply of affordable housing. Under LIHTC, private developers receive tax credits to create rent-restricted housing units rented to households with incomes averaging less than 60 percent of the AMI, and not exceeding 80 percent AMI. Between 1995 and 2015, 
LIHTC financed approximated 2.3 units projects, with about 41,000 units placed into service in 2015 (HUD 2017).

In the same spirit as LIHTC, local inclusionary zoning (IZ) policies aim to increase the supply of affordable housing by incentivizing developers to include affordable units in new developments. For example, IZ policies might allow developers to obtain permits more quickly, or build more units than allowed under existing zoning regulations, if a certain percentage of units in new projects are designated for low- and moderate-income households. ${ }^{12}$ These programs can be voluntary or mandatory. Montgomery County, Maryland adopted the first IZ program in 1974 (The Urban Institute 2012). By 2017, approximately 800 localities operated 1,400 IZ programs (Thaden and Wang 2017).

\section{Market-level interventions}

In addition to specific programs targeted to lower-income individuals and families experiencing homelessness, governments may implement market-level policies. In general, market-level interventions are less targeted, usually pertaining to all or most housing units in a jurisdiction with some exclusions by project age or size, though they may significantly affect homelessness through the price of housing.

Rent control limits the amount that landlords can receive for renting a home or apartment. In 2019, cities in five states (California, New Jersey, New York, Maryland, and Oregon) and the District of Columbia had some form of rent control, while 32 states had laws that preempt or prohibit rent control (National Multifamily Housing 2018). There are several general forms of rent control, with regulation details varying by city and state. Strict rent control, or vacancy control, limits the amount rents can increase between tenancies, while vacancy decontrol limits the year-to-year increase in rents a landlord can charge a returning tenant but allows the rent to increase to the market price between tenancies. For example, under the Costa-Hawkins Act, California state law prohibits strict rent control, but allows vacancy decontrol. New York City operates a system of vacancy decontrol, with the exact structure based on both date of tenancy and building age. While

\footnotetext{
12 Developments that do not have the required share of low-income units may access IZ benefits by paying a fee.
} 
rent control aims to increase housing affordability, it dampens incentives for landlords to invest or develop new units, and may reduce the overall supply of housing.

Market-level policies that restrict the supply of housing may increase prices and thus crowd out lowincome households (Glaeser, Gyourko, and Saks 2003, 2005; Gyourko et al. 2013); this in turn would increase the risk of homelessness. Zoning policies place restrictions on the numbers and types of units available in a given area. These policies vary across localities; for example, zoning ordinances may restrict the type of structure that can be constructed in an area: under single-use zoning, residences would not be permitted in commercial or industrial zones. Some jurisdictions, such as Washington, DC, put limits on the total height of structures, limiting the total potential number of units. Many economists argue that such zoning ordinances reduce the elasticity of housing supply, limiting the ability of the housing stock to respond when demand for housing increases which then increases renters' costs (Glaeser, Gyourko, and Saks 2005). Subsidized housing practitioners in high price cities often make a similar argument, noting that a lack of construction is the backdrop for their struggle to find housing for homeless clients.

By definition, market-level interventions affect all properties in a jurisdiction and are thus more difficult to evaluate. To our knowledge, there is no rigorous experimental or quasi-experimental work examining how these policies affect homelessness. Hence, we will skip this topic in Section IV and return to it in Section V.

\section{Evidence on the effectiveness of existing strategies}

Rigorous evidence on the effectiveness of homelessness prevention and mitigation strategies has grown over the past few years, though many gaps remain. While we will focus primarily on evaluations of particular programs and services, an existing literature studies homelessness at the community level. See Olsen and Zabel (2015) and O'Flaherty (2019) for more complete reviews of this literature. A few recent quasi-experimental papers examine whether additional resources for homelessness funding reduces the homeless population. Findings from this literature are mixed. Some work found that greater federal funding for supportive housing increased the number of people in sheltered housing and had no effect on the unsheltered population (Lucas 2017). On the other hand, Popov (2017) used a similar approach and found 
that when communities receive larger federal McKinney-Vento grants for homelessness programs, overall unsheltered homelessness decreases, and the number of beds increases. This aggregate effect, however, masks differences between individuals and families: unsheltered homelessness for singles drops unambiguously while families move to jurisdictions with greater resources such that both the sheltered and unsheltered populations increase with more generous funding. Other work found areas with more supportive housing beds have lower homeless counts (Corinth 2017). Finally, Evans et al. (2019) found that for each HUDVASH voucher distributed to a local area, beds for PSH increased by almost one bed per voucher and veterans' homelessness fell by one person per voucher. The remainder of this section considers particular strategies aimed at preventing and mitigating homelessness.

\section{A. Homelessness Prevention}

\section{Comprehensive interventions}

As discussed above, one strategy to reduce homelessness is to prevent those at-risk from entering homelessness. Recent quasi-experimental analyses have exploited variation in the availability of prevention services over time or across areas to measure the effect of prevention services on shelter entries and homelessness duration. One prominent example of a prevention program is Homebase, a resource for New York City families that connects clients with services such as family and landlord mediation, legal assistance, short-term financial assistance, child care, employment assistance, and mental health and substance use treatment. Goodman et al. (2016) used the gradual expansion of access to Homebase centers across neighborhoods between 2003 and 2008 and found that prevention services reduced the number of shelter entries by 5-11 percent. Rolston et al. (2013) randomly assigned 295 clients eligible for prevention services to either Homebase or a control group and also found that access to prevention services reduced shelter stays from an average of 32.2 nights in the control group to an average of 9.6 nights in the treatment group (a 70 percent reduction). However, this study could not detect a statistically significant change in SNAP and TANF receipt or family engagement with the child welfare system. 
The Homelessness Prevention Call Center (HPCC) in Chicago is typical of many prevention hotlines: only families whose financial problem can be handled with relatively limited funds (usually no more than $\$ 1,000)$ and have the means to pay for housing after the crisis recedes are eligible for funds. Among eligible clients, access to services depends on whether any participating agency has funds available for that client when the client calls. Unfortunately, funding for financial assistance is not always available and is unpredictable, which generates a comparison group of at-risk people who do not receive prevention services. Evans et al. (2016) exploit this variation to examine the impact of this program. They found that access to financial assistance reduced the rate of shelter entry within three months by 1.4 percentage points from a baseline of 1.6 percent (an 88 percent decrease), and that access to financial assistance reduced the time spent in a shelter over the next six months by 2.6 days from a baseline of 3.1 days (an 84 percent decrease). Using a similar empirical strategy, Palmer et al. (2019) found that access to emergency financial assistance reduced arrest rates for violent crime by 0.86 percentage points over the next three years, relative to a control group arrest rate of 3.7 percent (a 23 percent decrease). Among single individuals, emergency financial assistance also reduced rates of outdoor crimes that may be related to homelessness, such as trespassing and panhandling, by 1.0 percentage point from a control group rate of 0.78 percentage points. The authors also document a 1.0 percentage point increase in the probability of being arrested for a property crime three years after receiving assistance, relative to a control group rate of 1.9 percent (a 52.6 percent increase), which they interpret as some families incurring expenses that they are unable to afford.

\section{Critical Time Intervention}

Critical Time Intervention (CTI) programs provide case management and transitional services to individuals discharged from inpatient facilities. Given the relatively high rates of homelessness among this population, such services may reduce future spells of homelessness. Several RCTs have examined the effectiveness of CTI and discharge services, with mixed results. A relatively small RCT of individuals experiencing severe mental illness and histories of homelessness who were discharged from New York 
psychiatric hospitals found that individuals with access to CTI were five times less likely to experience homelessness eighteen months after discharge than those in the usual care group (Herman et al. 2011). Basu et al. (2012) examined the effects of case management during and after hospital discharge for individuals with a chronic medical illness who were experiencing homelessness. They found that discharge services reduced overall service costs by increasing housing stability and reduced most measures of medical care use (hospitalized days, ER visits, and nursing home stays), but the overall cost reduction of $\$ 6,300$ was not statistically different from average cost of usual care $(\$ 37,506)$. RCTs examining the effectiveness of CTI on families found improvements for children, measured by mental health, depressive symptoms, and selfreported trouble at school, up to about 0.5 standard deviations for internalizing and externalizing behaviors (Shinn et al. 2015), but no significant effect on maternal mental health (Samuels et al. 2015).

\section{Eviction court}

As we noted above in Section II, evictions are thought to represent a gateway into homelessness for many. ${ }^{13}$ As discussed in Section II, a persistent characteristic of eviction court is that few tenants enter proceedings with legal representation, while the vast majority of landlords are represented by attorneys. A few rigorous studies have examined the effect of providing full legal services to tenants facing eviction. In many cases, the status quo is that clients seeking legal aid services receive "unbundled" assistance that is more limited than a traditional attorney-client relationship, and may only include informational clinics summarizing the eviction process (Greiner et al. 2013).

Early experimental evidence on the effectiveness of full legal representation comes from a 1993-94 RCT, in which low-income tenants with rent non-payment were randomly assigned to receive full legal services. This study found that providing legal aid services increased court appearances by 22.5 percentage points, relative to a control group rate of 71.2 percent (32 percent); decreased unfavorable decisions by 29.1 percentage points (a 58 percent reduction from a control group rate of 50.6 percent); and eviction warrants by

\footnotetext{
${ }^{13}$ Desmond (2016) profiles low-income families in Milwaukee to show how high rent burdens and evictions can lead to homelessness.
} 
34.1 percentage points, relative to a control group rate of 44.1 percent (a 77 percent reduction) (Seron et al. 2001). Beyond maintaining housing, legal services also increased the likelihood that tenants obtained repairs (by 29 percentage points, relative to a control group rate of 2.3 percent) or rent abatement (by 38.4 percentage points relative to a control group rate of 25.4 percent). Full representation appeared to put little additional burden on the legal system: although case durations increased slightly, the number of postjudgment motions filed decreased, and there was no statistically significant change in the average number of court cases or the number of motions filed during trial. Another RCT in Boston in 2010 found similar effects: access to full legal services increased the likelihood that tenants remained in their units by 28 percentage points relative to a baseline of 38 percent (a 74 percent increase), and decreased the number of months of rent due by 7.5 months relative to the control group (Greiner et al. 2013). While case length duration increased, there was no statistically significant difference in the number of total motions or evidentiary hearings. However, a similar intervention to Greiner et al. (2013) on the North Shore of Massachusetts failed to find that full legal services improved housing circumstances (Greiner et al. 2012). The authors posit that these different results may be the result of assertive strategies adopted in Boston, versus a nonconfrontational approach on the North Shore. More work is needed in this area, particularly regarding legal tactics and the underlying housing market.

\section{B. Rapid Re-Housing}

\section{Non-experimental work on rapid re-housing}

Some observational studies have examined the effects of short-term housing vouchers for families experiencing homelessness. One prominent example is the Rapid Re-Housing for Homeless Families Demonstration Program (RRHFD) that provided rapid re-housing to families experiencing homelessness in 23 localities. ${ }^{14}$ Spellman et al. (2014) found that a year after receiving rapid re-housing services, 6 percent of families returned to shelter or transitional housing. Families that received more generous subsidies, or lived in areas with high vacancy rates were relatively less likely to return to a shelter. Looking over a longer period,

\footnotetext{
${ }^{14}$ For implementation details of this program, see Burt et al. (2016).
} 
Finkel et al. (2016) found that about 10 percent of families had another spell of homelessness within a year after the voucher expired. As RRHFD did not employ a comparison group, it is unclear how to interpret these findings.

The Supportive Services for Veteran Families (SSVF) intervention was another rapid re-housing program targeted to families experiencing homelessness. Work from that demonstration project found that within two years of receiving rapid re-housing services, 26 percent of individuals and 16 percent of veteran families had another spell of homelessness (Byrne et al. 2015). Homelessness was lower for participants who received assistance for more than 90 days, and those who received assistance with a security deposit. Again, as this study did not include a comparison group, it is difficult to interpret the magnitude of these findings.

Rodriguez and Eidelman (2017) used propensity score matching to examine the impact of households that received rapid re-housing, transitional housing, or emergency shelter services in Georgia. Compared to an initial assignment to emergency shelter, transitional housing and rapid re-housing recipients had a lower likelihood of returning to an emergency shelter within two years. The major caveat for this work is that the empirical method only controls for observed characteristics and does not deal with the fact that unobserved factors might be driving both assistance receipt and future housing stability.

\section{Family Options Study}

There is relatively little experimental evidence on rapid re-housing. One important exception is the recent Family Options Study that randomly assigned more than 2,200 families experiencing homelessness priority to receive different housing interventions in twelve communities. There were three interventions for which participants received priority: a permanent housing subsidy with no supportive services; a temporary rapid re-housing rental voucher for seven-eight months (renewable up to eighteen months) with limited housing search assistance; or transitional housing for up to 24 months with intensive supportive services. The control group was able to access existing assistance programs but did not receive priority access to any additional services or programs. Outcomes, including housing stability, family preservation, adult and child well-being, and economic self-sufficiency, were measured at twenty and 37 months after program entry. 
Gubits et al. (2013) noted that participating families had similar family structures and histories of homelessness to national surveys on families experiencing homelessness, suggesting these findings may be generalizable to the full population of families experiencing homelessness.

The Family Options Study provides the primary experimental test of the effectiveness of rapid rehousing $(\mathrm{RRH})$, but the results for this treatment arm are mixed. There were no statistically significant differences in housing outcomes between the control and short-term subsidy group by the three-year followup. (Gubits et al. 2016). Temporary subsidies slightly reduced the number of school absences, although this finding was no longer statistically significant after three years. Three years after entry, children had fewer instances of parent-reported problematic behaviors (Gubits et al. 2015, 2016).

Although the intent-to-treat point estimates of rapid re-housing from the Family Options Study suggest the program reduced entrances into homeless shelters, the results have large standard errors making it hard to say anything definitive about the impact of the intervention on this outcome. The statistically inconclusive results could be driven by an imperfect first stage as participants declined the treatment, referral agencies rejected clients as ineligible, or control group members accessed the treatment through normal channels. For long-term subsidies, these concerns were less important because the vast majority of those assigned to priority offers received long-term vouchers. In contrast, the first stage was weaker in the rapid rehousing arm. Twenty-two percent of the usual care group received rapid re-housing and only 58 percent of the treatment group ended up receiving rapid re-housing, meaning that assignment to treatment increased rapid re-housing rates by only 36 percentage points.

Similar to the RRH arm, a prioritized offer of project-based transitional housing showed few statistically significant results. The likelihood a family had any emergency shelter stay decreased by 40 percent (6 percentage points) relative to the usual care group, though this could be the direct effect of housing the family in transitional housing (Gubits et al. 2016). As with rapid re-housing, a lower take-up rate than permanent subsidies diluted the effects of treatment group status on outcomes.

While RRH and transitional housing generated statistically similar outcomes, rapid re-housing has lower long-term direct costs than both usual care and transitional housing. In the short run, project-based 
transitional housing cost approximately 44 percent less than usual care and rapid re-housing about 82 percent less (Gubits et al. 2015). Over three years, though, Gubits et al. (2016) found short-term subsidies cost 10 percent less than usual care and transitional housing was about 4 percent more expensive that the status quo. These results suggest that providing families subsidies for rental housing is more cost-efficient than the current system based on emergency shelters.

\section{Long-term rental vouchers (Section 8 or Housing Choice) \\ 1. General population studies}

There is a large literature on the effects of housing vouchers more generally and Housing Choice Vouchers in particular (Jacob et al. 2015; Jacob and Ludwig 2012; Sanbonmatsu et al. 2011; Kling et al. 2007; Chetty et al. 2016; Chyn 2018). A full description of this literature is beyond the scope of this paper; Collinson, Ellen, and Ludwig (2015) provides an overview. Here we limit the discussion to the effects of long-term vouchers on homelessness.

Perhaps the best-known intervention is the Moving to Opportunity (MTO) demonstration, a tenyear study that provided housing vouchers to low-income families living in public housing projects. The MTO final evaluation concluded that voucher receipt slightly improved housing quality and reduced the likelihood of families reporting difficulty in paying rent, although compared to families in public housing, vouchers had no detectable effects on the likelihood that families were literally homeless (Sanbonmatsu et al. 2011).

Other experimental work shows that vouchers can reduce homelessness and improve housing outcomes. For example, the San Diego McKinney Homeless Research Demonstration Project, (Hurlburt et al. 1996) found access to a Section 8 voucher increased the likelihood of living in stable housing by 29 percentage points from a baseline of 31 percent (a 93 percent increase) over a two-year period. Likewise, for current and former welfare recipients, Welfare to Work vouchers reduced homelessness—-defined as living on the streets, in shelters or with friends or relatives—after four years by 36 percentage points from a baseline of 45 percent (a 80 percent decrease) and reduced rates of overcrowding — defined as living with less than one 
room per person in the household—by 22 percentage points from a baseline of 46 percent (a 48 percent reduction) (Wood et al. 2008). Welfare to Work voucher recipients also moved to higher-income neighborhoods and experienced fewer moves over a four-year period. The effects for children, however, were somewhat mixed: while school absenteeism decreased, grade retention increased and there was no significant change in children's time use (Mills et al. 2006). Importantly, each of these demonstration programs affected a small fraction of low-income tenants in the local housing market and therefore cannot speak to any general equilibrium effects of greater voucher availability or higher subsidy rates. We return to this point in Section V.

\section{Family Options Study}

While MTO and Welfare to Work examined housing outcomes for a low-income population that was at-risk for homelessness, there is relatively little experimental evidence on long-term vouchers targeted to families and individuals experiencing homelessness. As with rapid re-housing, the Family Options Study provides the primary evidence. Recall that Family Options also included a long-term voucher treatment arm, typically a Housing Choice Voucher. For most outcomes, being prioritized for permanent subsidies led to larger improvements in family well-being than prioritization for either temporary subsidies or transitional housing (Gubits et al. 2016). Throughout the three-year follow-up period, families with priority access to long-term subsidies had improved housing outcomes. Specifically, access to subsidies reduced the likelihood of being homeless or doubled-up in the past six months by 18 percentage points relative to a baseline of 34 percent (a 53 percent decrease) and reduced the likelihood of an emergency shelter stay during the past year by 14 percentage points from a baseline of 19 percent (a 78 percent decrease). (Gubits et al. 2015, 2016, 2018).

Priority access to temporary and permanent subsidies resulted in some improvements in family and adult well-being on non-housing dimensions. After twenty months, access to long-term subsidies reduced the fraction of families with a child removed from the home (among those separated from a child at baseline) by 7 percentage points, compared to 17 percent among the usual care group (a 41 percent decrease), although this effect was no longer significant after 36 months. By some measures, adult well-being also improved, 
although these benefits appeared to fade over time. Three years after random assignment, psychological distress fell by approximately 0.7 points on the K6 scale for those with access to permanent subsidies (Gubits et al. 2018). Families with access to permanent vouchers were 38 percentage points more likely than the usual care group to be separated from a partner or spouse three years after program entry, representing a 13 percentage point increase from a baseline of 34 percent. Coupled with a slight reduction in the share of adults reporting domestic violence in the past six months, as well as high rates of intimate partner violence among this population, this finding is consistent with permanent subsidies allowing recipients to leave unsafe or harmful situations.

Access to a permanent subsidy reduced the number of schools children attended from an average of 2.04 in the usual care group to an average of 1.89 in the permanent subsidy group over the three-year study period. In the medium term (20 months), they also reduced the monthly number of school absences from an average of 1.04 in the usual care group to an average of 0.84 in the permanent subsidy group, although this finding was no longer statistically significant after three years. Three years after entry, children in the subsidy group also had fewer instances of parent-reported problematic behaviors such as emotional symptoms, conduct problems, hyperactivity, and peer problems (Gubits et al. 2016, 2018).

Access to housing also affected families' economic well-being. Families with access to permanent subsidies were 6 percentage points less likely to be employed 20 months after entry from a baseline of 30 percent (a 19 percent reduction) compared to families without access to the subsidies, although this difference disappeared three years after randomization (Gubits et al. 2015, 2016, 2018). At both twenty and 37 months, temporary and permanent subsidies improved food security by 10 percentage points, representing a 20 percent increase from a baseline of 52 percent (Gubits et al. 2015, 2016, 2018).

While long-term subsidies led to the most consistent benefits, these improvements came at a cost. Long-term subsidies were the most expensive arm of the Family Options Study, costing 9 percent more than usual care, with the cost differential increasing over time (Gubits et al. 2016, 2018). This widening gap is driven by the length of the intervention: while per-month shelter costs were less for long-term subsidy 
recipients than emergency shelter or transitional housing, participants tended to access subsidies for longer periods of time.

\section{Experimental Evidence on Supportive Housing \\ 1. Pathways to Housing}

One of the earliest supportive housing programs was the Consumer Preference Supported Housing Model developed by Pathways to Housing (Pathways) in New York City. Pathways provided supportive housing in individual housing units to persons diagnosed with a mental health disorder who were experiencing homelessness. Importantly, in contrast to traditional programs, participation in psychiatric treatment was not a pre-condition for receiving housing services. ${ }^{15}$

Two to three years after random assignment, clients with access to supportive housing who previously experienced street homelessness had lower rates of homelessness and spent about half as much time homeless and in hospitals than those receiving traditional services (Gulcur et al. 2003; Greenwood et al. 2005). Given the characteristics of the study population, many of the outcomes examined in the Pathways study focused on use of mental health and treatment options. Over a four-year follow-up period, there was no significant effect of supportive housing on substance use or psychiatric symptoms (Tsemberis et al. 2004; Padgett et al. 2006). These findings are consistent with earlier, non-experimental work that found lower rates of homelessness for Pathways clients, compared to individuals experiencing homelessness who did not access Pathways services (Tsemberis and Eisenberg 2000).

\section{At Home/Chez Soi}

Other jurisdictions have evaluated supportive housing programs similar to the Pathways model. The largest of these was the At Home/Chez Soi RCT that operated over five years across five Canadian cities. ${ }^{16}$ The program enrolled 2,148 individuals with severe mental illness who were experiencing homelessness.

15 Tsemberis (1999) and Tsemberis and Asmussen (1997) provide a comprehensive description of the Pathways program and the clients it served. Pearson et al. (2007) describe similar programs in other communities.

16 The cities were Vancouver, Winnipeg, Toronto, Montreal, and Moncton. 
Treatment group participants received subsidized, community-based, independent housing, with mental health and supportive services provided by community teams. Control group individuals continued to have access to other housing and support services available in their communities. Both Pathways and At Home/Chez Soi provided similar housing and supportive services to "high-need" individuals, but At Home/Chez Soi also included a treatment arm of less-intensive case management for moderate-needs recipients. ${ }^{17}$

The At Home/Chez Soi study shows supportive housing improved housing outcomes throughout the follow-up period. Two years after random assignment, those assigned to supportive housing had spent twice as much time stably housed (compared to about 32 percent among control group members) and experienced fewer moves than individuals in the treatment as usual group (Goering et al. 2012, 2014; Aubry et al. 2015; Stergiopoulos et al. 2015), and effects were similar for younger (18-49) and older (50+) clients (Chung et al. 2017).

The treatment group also showed improvements in non-housing outcomes, such as quality of life and community functioning the first year after random assignment, although differences were no longer statistically significant by the end of the second year in the pooled sample for most groups (Aubry et al. 2015). ${ }^{18}$ In the Vancouver site, supportive housing also reduced emergency department use one year after program entry by about half (relative to a control group average of seven visits a year) (Currie et al. 2014), while the Toronto site reported reductions in alcohol use over a two-year period (Kirst et al. 2015; Stergiopoulos et al. 2015).

Over the short-term, more than half (54 percent) of the costs of providing supportive housing were recouped through lower expenditures on health care and shelter systems (Goering et al. 2012). Most of these cost reductions were driven by clients with high-systems use: among those who had systems use above the

\footnotetext{
${ }^{17}$ Goering et al. $(2011,2012)$ provide a program overview and describe baseline characteristics of participants. ${ }^{18}$ Some sites, such as Toronto, continued to show improvements in community functioning two years after program entry (Stergiopoulos 2015). In addition, older clients experienced greater improvements in mental health and some measures of quality of life (Chung et al. 2017).
} 
$90^{\text {th }}$ percentile of the cost distribution three- six months before random assignment, supportive housing was less than half the cost of providing treatment as usual (Goering et al. 2014).19

3. Veterans Affairs Supportive Housing (HUD-VASH)

Additional experimental evidence that supportive housing improves housing outcomes comes from HUD-VASH. Several pieces of experimental work show that HUD-VASH reduces homelessness, but has mixed effects on other outcomes. The original RCT of the program enrolled 460 chronically homeless veterans with substance use and/or psychiatric disorders. At the end of the three-year follow-up period, individuals with access to the combined treatment of housing vouchers and case management had spent 7.4 fewer days homeless in the previous ninety days compared to individuals receiving usual care (36 percent reduction) (Rosenheck et al., 2003). Case management services without a housing voucher did not significantly affect housing outcomes. The reduction in homelessness for the dual-treatment group was particularly pronounced in the first two years after program entry and attenuated over time. O'Connell et al. (2012) examined heterogeneity in treatment effects and found that vouchers had the largest housing benefits for white individuals, individuals with co-occurring disorders, and active substance users.

While HUD-VASH improved housing outcomes, it did not significantly affect medical costs or criminal justice expenditures (Rosenheck et al. 2003). Results for psychiatric health, substance use, and community adjustment are also statistically imprecise and cannot rule out meaningful changes in either direction. A smaller RCT confirmed these main conclusions, concluding that HUD-VASH reduced the time to stable housing from six months to one month and led to an eight-fold increase in the likelihood of maintaining stable housing for a full year, while increasing the number of inpatient mental health days without affecting urgent care use (Montgomery et al. 2013).

\section{Additional experimental evidence}

19 The authors did not test whether this difference was statistically significant. 
In addition to the Pathways, Chez Soi, and HUD-VASH studies, several smaller experiments have examined the extent to which supportive housing affects housing stability and engagement with mental health and substance use treatment. In general, this literature has focused on individuals experiencing homelessness who have mental health and/or substance use disorders. As noted in Table 1, persons with mental health or substance use disorders may be of particular policy relevance, as these individuals have high rates of homelessness. As many of these individuals engage with other systems, such as criminal justice, health care, and housing services, addressing homelessness among individuals experiencing severe mental illness or substance use disorders may result in cost offsets in other systems as well (Culhane, 2008).

In general, this work found that supportive housing improves housing outcomes relative to usual care by increasing housing stability and reducing the number of days spent homeless. Goldfinger et al. (1999) randomly assigned a small sample of individuals diagnosed with illness experiencing homelessness to either supportive housing with on-site services or independent housing and found greater reductions in homelessness for the supportive housing group. Although this study contained no true control group, the difference in outcomes between individuals assigned to supportive housing compared to individuals assigned to independent housing is informative. Over 18 months, individuals assigned to supportive housing experienced homeless for 43 days, compared to 78 days among those in independent housing (a 45 percent reduction). In addition, some work found that supportive housing reduced the use of emergency medical systems and improved other health outcomes (Wolitski et al. 2010; Milby et al. 2005; Kertesz et al. 2007).

\section{Evidence from observational studies}

A number of observational studies have examined associations between supportive housing programs and client outcomes. The studies highlighted here attempt to account for observed confounding factors that may affect service take-up. This approach is problematic since unobserved characteristics might affect an individual's likelihood of receiving supportive housing, and also their future housing and economic outcomes. For example, participation in most supportive housing is conditioned on the clients having experienced a period of homelessness prior to participation. As most spells of homelessness are temporary, 
some of these spells would have ended even without intervention. Consistent with this point, experimental evidence shows reduced rates of homelessness and increased housing stability for control groups over time, relative to their initial housing situation (Rosenheck et al. 2003; Goering et al. 2014; Gulcur et al. 2003).

Through the New York/New York Agreement to House the Homeless Mentally Ill (NY/NY), individuals experiencing chronic homelessness and mental illness were provided with supportive housing through scattered site housing, with supportive services provided in the community or on-site. ${ }^{20}$ As the NY/NY program did not include an experimental component, Culhane et al. (2002) examined program impacts with a matched-pairs design to create a control group with similar demographic characteristics, mental health and substance use risk, and service use to individuals who received supportive housing services. They found that supportive housing significantly reduced hospitalizations, use of medical services, incarcerations, and the number of days spent in a shelter over a two-year period. An important contribution of Culhane et al. (2002) is the extensive use of administrative data from multiple service agencies. These data allow the authors to draw on a relatively large sample and obtain accurate information on the typical costs of services used. Combining the utilization estimates with average service costs, the authors estimate that after accounting for reductions in service use, supportive housing was 2.5 percent more expensive than providing services through usual care (\$995 per year in 1999 dollars). The largest cost savings came from reductions in mental health services.

The Frequent Users Services Enhancement (FUSE) provided supportive housing to another highcost group in New York City: individuals who had multiple spells of homelessness and instances of engagement with the criminal justice system. Like NY/NY, FUSE did not include an experimental component, but Aidala et al. (2013) conducted an analysis with propensity score matching on a group of individuals who were FUSE-eligible but did not receive treatment. Over a 24-month period, those with access to supportive housing were less likely to experience homelessness, although the gap between the treatment

\footnotetext{
${ }^{20}$ HUD defines chronic homelessness as a "homeless individual with a disabling condition who has been continuously homeless for a year or more, or an unaccompanied individual with a disabling condition who has had at least four episodes of homelessness in the past three years" (HUD, 2007).
} 
and control group narrowed over time. Those with supportive housing also had fewer incarcerations and lower rates of hard drug use at follow-up.

The federal Collaborative Initiative to Help End Chronic Homelessness (CICH) was piloted in eleven communities and provided supportive housing to individuals experiencing chronic homelessness. While the pilot did not involve an experimental component, during the program's second year, a small comparison group was selected from five sites (Mares and Rosenheck 2011). Although the control group was screened to meet the $\mathrm{CICH}$ requirements, on average they had significantly lower rates of mental health problems and had spent less time homeless than the treatment group. Mares and Rosenheck (2011) include control variables for these differences, but the systematic differences between treatment and control groups suggest these groups may have had different trajectories regardless of the intervention. With these caveats in mind, $\mathrm{CICH}$ clients accessed more case management, mental health, and substance abuse services. Those in the supportive housing group also spent more time stably housed, and fewer days hospitalized or incarcerated.

\section{Key questions that can be addressed in future research \\ A. Can we expand the pool of evidence about what programs improve housing stability?}

An increasing collection of rigorous evidence confirms that existing homelessness programs meet their most immediate objective: promoting housing stability. As outlined above, financial assistance and comprehensive interventions can prevent homelessness (Rolston et al. 2013; Evans et al. 2016). Legal assistance can reduce the chance of eviction (Seron et al. 2001; Greiner et al. 2013). More broadly, long-term Section 8/Housing Choice vouchers can both prevent homelessness (Hurlburt et al. 1996; Wood et al. 2008) and effectively re-house families experiencing homelessness (Gubits et al., 2016, 2018). Even for cases where people are both experiencing homelessness and facing behavioral health challenges, permanent supportive housing can increase housing stability through a combination of long-term subsidies and supportive services (Gulcur et al. 2003; Greenwood et al. 2005; Goering et al. 2012, 2014; Aubry et al. 2015; Stergiopoulos et al. 2015). 
Despite these positive results, there is less evidence about some existing programs. For example, there is conflicting evidence on whether rapid re-housing (RRH) promotes housing stability. By far the best evidence comes from the Family Options Study (Gubits et al. 2016, 2018), and the point estimates from this study suggest that the program reduced entrances into homeless shelters. However, large standard errors in the intent-to-treat (ITT) models combined with low program take-up make it hard to say anything definitive about the impact of this intervention on housing stability. About 58 percent of the treatment group received RRH, but since 22 percent of the usual care control group also received RRH, the experiment only increased participation in RRH by 36 percentage points. Thus, when (Gubits et al. 2016) found an ITT effect of $2.0 \pm 4.3$ percentage points for the six-month shelter entry rate, this corresponded to roughly a $-5.6 \pm 12.0$ TOT effect of RRH. Given a control group shelter entry rate of 8.8 percent, it is difficult to make strong conclusions about how short-term subsidies affect homelessness. Future studies could solve this power challenge with a much larger sample or, likely more practical, an environment with a stronger first-stage relationship. Given the dramatic shift toward housing first models across the country, a priority research area must be identifying the impact of RRH on housing outcomes.

Two recent quasi-experimental studies, one in New York (Collinson and Reed 2018) and another in Chicago (Humphries et al. 2018) provide convincing evidence that eviction leads to tremendous housing instability, including a pronounced increase in homelessness. A possible response is to change the dynamics of housing court and provide legal representation to tenants who typically are not represented in these hearings. Cities from Cleveland to Philadelphia are considering reforms that would provide tenants with greater representation in housing court. The most aggressive reform has been in New York, where the DeBlasio administration has adopted legislation that would guarantee all tenants under 200 percent of the Federal Poverty Line legal representation in housing court. While existing evidence shows that legal representation can improve tenants' housing court outcomes (Seron et al. 2001; Greiner et al. 2013), these have not been linked to longer-term housing stability. These recent policy changes provide a unique opportunity to answer some of the questions outlined above. Unfortunately, the New York experience is not being implemented in a way that allows for random assignment. That said, given the cost and the scope of the 
intervention, implementation is being rolled out zip code by zip code. As a result, some quasi-experimental analysis is possible. If legal representation can alter eviction rates, then evictions' impacts on housing and down-stream outcomes could potentially be identified. Exploiting the New York experience or convincing an enterprising city to run an RCT that provides legal counsel could potentially answer many questions.

A limitation of existing work on housing stability is that many studies measure whether an individual enters the shelters or the HMIS homeless data system as the key outcome (Rolston et al. 2013; Evans et al. 2016). This strategy is practical because many jurisdictions already track shelter entry, and this outcome is inexpensive to collect from administrative data. Shelter entry is, however, an uncommon and extreme outcome that misses most cases of housing instability. In the Family Options usual care control group, four times as many people report being homeless or doubled-up (35 percent) as entering a shelter (9 percent) (Gubits et al. 2016). Surveys can solve this data problem (e.g. Goering et al. 2014; Gubits et al. 2016), but surveying unstably-housed individuals is expensive and may have high non-response rates, though wellfunded studies such as Family Options have managed response rates to in-person surveys around 75 percent. Given the drawbacks of shelter data and the expense of surveys, measurement is an important area in need of progress. One possible solution is to use address histories from more widely-available sources, such as consumer reference data. Some initial attempts to measure housing stability with this data are encouraging (Diamond et al. 2018; Phillips 2019), but more research is needed. Better and cheaper options for measuring housing stability in general and homelessness particular would relax an important constraint to rigorous work in this area.

\section{B. What outcomes beyond housing are improved by existing programs?}

Although most of the interventions discussed above are primarily designed to alter housing outcomes, many are expected to impact other outcomes as well. The potential list of variables altered by improved housing is large, including medical care use, health, employment and earnings, social insurance use, criminal justice involvement, and children's schooling, to name a few. Unfortunately, examining impacts on these outcomes is difficult. As these outcomes are further down the causal chain (e.g., treatment alters 
housing, housing alters compliance with a medical treatment regime, improved medical care reduces hospital admissions, etc.), statistical power falls considerably. Boosting power by expanding the sample size is expensive for costly interventions such as RRH and PSH. Monthly per-family costs of supportive services in Family Options ranged from an estimated $\$ 1,172$ for housing subsidies to $\$ 2,706$ for project-based transitional housing. Evaluation costs also increase if outcome data relies on expensive in-person surveys. This means that many studies have relied heavily on administrative data to track outcomes (e.g., arrests, hospital admission, emergency department use, VA medical claims, labor market earnings as recorded in unemployment insurance system, etc.). Unfortunately, administrative data in the US are not available for all outcomes, and most administrative data sets are state-based so that clients are no longer recorded if they move out of state. It is often impossible to differentiate between, for example, no earnings within a quarter and someone moving out of state.

It is then no surprise that fewer studies rigorously measure the effect of homelessness programs on outcomes beyond housing stability. In the review above we found few rigorous studies documenting a measurable causal effect of homelessness prevention, legal assistance, RRH, or permanent supportive housing interventions on non-housing outcomes. A template for homelessness research is the work on Section 8/Housing Choice Voucher program, where a large literature examines the effect of a voucher versus various alternatives on children's well-being, criminal behavior, health, employment, and so on (Katz et al. 2011; Jacob and Ludwig 2012; Jacob et al. 2015; Chetty et al. 2016; Gubits et al. 2016; Chyn 2018). The lack of evidence on programs more specifically targeted at homelessness is surprising. Housing first approaches and prevention programs both argue that stable housing provides a platform for success in other areas of life, yet very little rigorous evidence tests whether this claim is true.

In those studies that have examine non-housing related outcomes, in many cases there are few downstream outcomes with statistically significant results. For example, many predicted that housing first models would reduce the high medical costs of the chronically homeless. Despite the RCTs in this sphere, there is little credible evidence that interventions such as PSH do in fact improve health and reduce medical costs (National Academies of Science, Engineering and Medicine 2018). In their HUD-VASH experiments, 
Rosenheck et al. (2003) found VA medical costs increased as a result of receiving a voucher, although the results were statistically insignificant. Studies of homelessness prevention (Rolston et al., 2013) and RRH (Gubits et al. 2016) measure outcomes beyond housing stability but typically can reject neither zero nor very large effects on these outcomes. In a Housing First experiment with case management in Chicago, Basu et al. (2012) calculated societal costs of homelessness including health care use, justice system, and social program participation. They found Housing First reduced social costs by $\$ 6,300$, but the results were statistically insignificant.

For costs in particular, statistical power is a real concern. For example, Rosenheck et al. (2003) measure mean VA medical costs of $\$ 28,515$ over three years for a usual care control group with results that imply a standard deviation of $\$ 33,902$. With these data, even with perfect compliance a 500 -person trial could detect an $\$ 8,500$ decrease in total medical costs or about a 30 percent reduction in spending. For comparison, the voucher component of the HUD-VASH program is about $\$ 7,000$ per year. Given the sample sizes of traditional experiments in this domain, it is only be possible to detect statistically significant changes in medical costs if the cost savings are massive.

The work on the impact of evictions cited above provides convincing evidence that evictions lead to more homelessness but unfortunately, in both Chicago and New York, the variation in evictions generated by judge assignment was not large enough to identify many definitive claims about long-term outcomes such as earnings, arrests, or SNAP use. To date, the literature provides little evidence on housing stability beyond the court's immediate decision. Again, the phased roll-out of the New York City program to provide representation to all tenants in eviction court under 200 percent of the poverty line may provide some evidence of the non-housing outcomes of legal representation. A large, well-designed RCT that provides increased access to legal services for tenants may also answer these questions.

In other cases, some of the most potentially important outcomes are left unmeasured. Long-term outcomes for children provide perhaps the starkest example. Research on Moving to Opportunity (Chetty et al. 2016) and public housing demolitions (Chyn 2018) showed that moving to more affluent neighborhoods can dramatically affect the long-term economic success of children. Similar effects may exist for homelessness 
interventions, and such an effect would matter for both cost-benefit analysis and policy discussions. However, to our knowledge no rigorous study measures the causal effect of a homelessness mitigation or prevention program on children's long-term outcomes. Even studies measuring short-term effects on children are rare, though they exist (e.g. Gubits et al. 2016). Many practical obstacles prevent progress on measuring children's long-run outcomes including an inability to link data over time, requisite long planning horizons, and greater privacy and consent concerns for children. Similar gaps in the literature exist for other outcomes that could also turn the result of a cost-benefit analysis. Healthcare, mortality, and crime all exert large social costs, and individuals experiencing homelessness interact heavily with these systems (Flaming et al. 2015). However, statistically significant effects for these outcomes are particularly rare in the literature, with very limited exceptions (e.g. Palmer et al. 2019). Surprisingly limited evidence exists on whether homelessness interventions affect the outcomes that likely matter most to a cost-benefit analysis.

\section{What bundle of services are most effective and for whom?}

Homelessness services are very expensive. The average cost of a HUD-VASH voucher in 2016 was a little over $\$ 7,000$ per year, excluding the cost of supportive services provided by the VA system (NHIP, 2016). As we noted above, the monthly costs for Family Options ranged from $\$ 1,200$ to $\$ 2,700$. Thus, there is likely considerable room for marginal changes to make existing homelessness programs more costeffective. Coordinated policymaking at a federal and local level raises two natural topics: bundling services and targeting.

In many situations, homelessness interventions have multiple components. For example, PSH pairs housing with case management. Improving the cost-effectiveness of these programs might entail pulling these components apart and determining which ones are delivering outcomes and which ones are not. Some effort has been made along this dimension. In the original work on HUD-VASH, Rosenheck et al. (2003) had two treatments, PSH and case management (CM) only. For most outcomes, CM did no better than the standard care comparison, especially on housing, health and employment. That said, the sample frame for that study was veterans with mental illness or substance use disorders experiencing chronic homelessness, so both 
housing and support may be critical for that population. For less acute homelessness, CM by itself or rapid rehousing without $\mathrm{CM}$ could prove a more cost effective alternative. In another example that attempted to tease apart elements of an intervention, Somers et al. (2017) investigated a Housing First model in the Vancouver At Home study in both scattered site and congregate formats compared to treatment as usual. While they found that both scattered site and congregate formats achieved housing stability among people experiencing major mental illness and chronic homelessness, only the congregate format was associated with improvements on certain secondary outcomes.

Many of the interventions discussed above are complex and rigorous studies that attempt to unbundle overall program effects are not common. For example, Homebase (Rolston et al. 2013) provides a broad package of financial assistance, case management, and connection to other services. Rapid re-housing provides temporary housing subsidies bundled with some supportive services. The exact nature of these services varies widely across communities in both the HUD Rapid Re-Housing Demonstration and Family Options Study (Burt et al. 2016; Gubits et al. 2016), and a tenant's success in leasing housing and successfully continuing a lease after subsidies end may depend on what support they receive with housing search and employment. To our knowledge, there is no experimental work separating the effects of these components.

Targeting the correct treatment to the correct person also matters for cost effectiveness.

Homelessness is a rare event, even for the people at risk of homelessness targeted in many of the studies discussed above. Consider the work of Evans et al. (2016) who show that short-term financial assistance offered to families on the verge of losing their home or apartment can reduce entry into homelessness by 76 percent. Despite the success of this program, only about 2 percent of families in the group not offered assistance end up in a shelter. As the vast majority of grant recipients will not enter homelessness, better targeting of the benefits to those most at risk will improve the cost effectiveness of the program considerably. Some existing evidence indicates that data can be used to improve targeting (Shinn et al. 2013).

There are many groups of people over-represented in the homeless population, such as veterans, individuals with substance use disorders, individuals with serious mental health issues, released prisoners, families with children, etc. Each group has potentially different needs and tailoring a PSH or RRH program 
for each group could be quite different. Single-parent families experiencing homelessness and facing temporary shocks may need only a relatively limited RRH program with short-term case management and temporary housing support to stabilize their situation. In contrast, individuals released from incarceration in the same RRH program may need more continued supports as obtaining permanent employment may be more challenging.

The problem of individuals recently released from incarceration is of particular interest. About 600,000 people are released from prison each year and another nine million are released from jail. Of those released from prison in 2005, about two-thirds were arrested within three years of release. Those formerly incarcerated become homeless at ten times the rate of the general population (Couloute 2018). Poor postrelease employment opportunities likely make stable housing options worse for this group. The intersection of homelessness and prisoner re-entry will become more of an issue in the future. First, there is an effort to find alternatives to incarceration, encouraging states and the federal government to release non-violent offenders in higher numbers. The recent federal bipartisan prison reforms are one example. If the conditions under which prisoners are released are not altered, then we might transfer an incarceration problem into a homeless problem. The efforts in California around Proposition 47 are instructive. Passed in 2014, Proposition 47 released 13,000 low-level, non-violent offenders from over-crowded prisons and jails, many with histories of substance use and mental illness. How best to serve this population is a key research issue given the high cost of recidivism for this group.

\section{Can researchers evaluate and exploit the structure of coordinated entry?}

Despite the organizational capacity started by the $\mathrm{CoC}$ model, in many local jurisdictions, there was historically little coordination across agencies in prioritizing who should receive the scarce resources for homelessness. Around 2010, many CoCs began establishing a centralized and coordinated assessment system intended to prioritize which people receive services, and in July 2012, the CoC Interim Rule required all CoCs establish a Coordinated Entry System (CES) and coordinated assessment system. Coordinated entry helps 
communities prioritize assistance based on vulnerability and service needs so that clients that need assistance the most can receive it in a timely manner.

An important research question is whether the system of coordinated entry is generating different outcomes than the more diffuse system that has historically been used. How has this changed what groups are getting services? Are outcomes different now with coordinated entry? Unfortunately, evaluating the overall impact of CES is made difficult by the group nature of the intervention and the most-likely nonrandom way that CoCs adopt CES. The window to evaluate how CES alters outcomes via an RCT design has most likely closed and any analysis on this question will likely be accomplished with non-experimental methods.

Coordinated entry does, however, generate greater potential for answering the two sets of questions outlined above. As potential clients enter a $\mathrm{CoC}$ through a central portal, the opportunities to evaluate through random assignment are enhanced greatly. A CES system makes randomization across many diffuse agencies possible and facilitates data collection easier by forcing all participating agencies into the common HMIS data system. While researchers have made extensive use of HMIS data, less work has leveraged the centralized structure of coordinated entry.

Most ambitiously, the machinery of coordinated entry could be used to address the questions of targeting and matching clients to programs. The variety of potential interventions and the challenge of matching programs to individuals suggest a research agenda that combines experimental and predictive tools to optimize coordinated entry. For people who are already experiencing homelessness, many jurisdictions follow HUD guidelines in triage. A common system is as follows: a risk tool based on stated responses of risk factors assigns a score. Such tools may be validated by checking if higher scores predict homelessness prior to implementation. The coordinated entry system then assigns the highest risk cases to PSH, middle risk cases to $\mathrm{RRH}$, and low risk cases to much less intensive services. Within each group, the highest risk cases are often prioritized.

Such a system makes several assumptions. First, targeting high risk individuals also targets individuals with large treatment effects. Second, stated responses are more reliable predictors of treatment effects than 
existing administrative data or case worker opinions. Third, respondents do not manipulate stated responses when the tool is used to assign treatment. Fourth, clients can be summarized by a one-dimensional risk score where higher risk means more services are better.

One can imagine a much different system, driven by administrative data, experimental variation, and machine learning prediction tools. Some measure of random variation would be introduced at the margin to observe outcomes for clients in treatments counterfactual to the current system of rules. Existing coordinated entry data would be matched to other administrative data on shelter entry, arrests, medical care, etc. Then, using recent developments combining machine learning with a treatment effects framework (Athey and Imbens, 2016), a model could be developed that predicts treatment effects for an individual based on their individual characteristics. Obviously, such an effort would require large sample sizes, centralized data collection, and extensive collaboration between researchers and practitioners. Any such system would also have to explicitly identify and address potential trade-offs between equity and efficiency. However, the existence of coordinated entry and recent econometric developments make this type of idealized coordinated entry system at least a possibility.

\section{E. Can supply-side interventions work?}

While the literature largely measures the effectiveness of interventions targeted at tenants, the supply of housing may be just as important. As discussed in section I, homelessness has increased more in cities like New York, Los Angeles, San Francisco, and Seattle. Restricted housing supply could cause higher rents and greater homelessness in these places. However, we have little evidence on how policies relaxing housing supply restrictions would affect homelessness. Ambitious policy changes have been promoted to increase supply of housing and decrease rents. Perhaps most prominently, the California state government has extensively debated bills to prevent local governments from blocking high density development near transit (Dougherty 2018). The existing literature primarily documents a clear, positive cross-sectional relationship among zoning restrictions, rent levels, and homelessness across locations (Quigley, Raphael and Smolensky 2001; Raphael 2010). However, as seen in Section II, recent changes in rent levels show almost no correlation 
with homelessness across CoCs. To our knowledge, no rigorous studies provide evidence on how much homelessness can be attributed to rent increases and restrictions on supply. This is a clear gap in the literature.

At the micro level, evidence on how landlords interact with homelessness interventions would be helpful. From the literature on long-term Section 8/Housing Choice vouchers, we know that landlords are very reluctant to participate in market-based subsidy programs. Multiple correspondence and audit studies demonstrate that many landlords avoid tenants who want to pay with a voucher (Phillips 2017; Moore 2018; Cunningham et al. 2018). In-depth qualitative work suggests that some landlords specialize in taking voucher tenants when the voucher pays above market and/or offers reliable payment relative to a counterfactual with low-income cash tenants. But many more landlords avoid the program due to bureaucratic delays, inspections, and a perceived greater risk of damage or eviction (Rosen 2014; Garboden et al. 2018). Most major homelessness interventions also interact with landlords. Rapid re-housing and permanent supportive housing programs often place tenants in market units. The challenges faced by Section 8 vouchers are likely amplified when placing tenants with shorter duration subsidies, histories of homelessness, and/or behavioral health issues.

In our review of the literature on homelessness, we found no rigorous studies evaluating interventions or components of interventions targeted primarily at landlords. Even in the Section 8/Housing Choice voucher program, only a couple of studies examine how landlords respond to voucher payment amounts (Collinson and Ganong 2018; Aliprantis et al. 2018) and source-of-income non-discrimination laws (Freeman 2012; Freeman and Li 2014). This lack of evidence persists despite the fact that programs often engage intensively with landlords. The HUD Rapid Re-Housing Demonstration (Burt et al. 2016) reports that RRH programs typically conduct landlord outreach and education, maintain databases of interested landlords, help match individual clients with landlords, and even sometimes coordinate with units receiving supply-side subsidies from public or private sources. Other programs attempt to defray landlord risks by doubling security deposits or insuring any damage to units caused by program tenants. Landlords likely play an important role in homelessness, but we have little evidence on what supply-side interventions are effective. 


\section{F. What are the general equilibrium effects of homelessness interventions?}

The vast majority of rigorous studies of homelessness policy measure partial equilibrium effects. When a randomized control trial compares housing outcomes for a treatment group and a control group within the same housing market, the study can only measure whether the treatment group benefits relative to the control group. It cannot determine if the program affected the housing market overall, though many such effects are plausible. New housing programs could increase prices, encourage migration of homeless individuals into the market, crowd out other homelessness programs, and so on.

Only a handful of studies measure market-level effects, and all of these studies focus on overall homeless counts. To review from above, Popov (2017) and Lucas (2017) both study the effect of federal homelessness funding at the market level with a similar empirical strategy but found different results about whether assigning greater funding levels to a community reduces overall homelessness there. Corinth (2017) found evidence that communities with more permanent supportive housing beds have smaller homeless counts, albeit with significant crowd out. Evans et al. (2019) found that each federal HUD-VASH bed reduced homeless counts by one person experiencing homelessness. While the literature provides some mixed evidence on how overall funding levels affect homeless counts, netting out both direct program effects and general equilibrium effects, it provides little direct evidence on particular general equilibrium mechanisms of homelessness policies.

Large-scale increases in subsidies for individuals experiencing homelessness may increase prices, particularly in places with restricted supply. In an extreme housing market with perfectly inelastic housing supply, a large increase in housing subsidies rearranges who gets housing and transfers income to landlords without changing the overall stock of housing. A large literature examines the price effect of subsidies in the context of Housing Choice Vouchers. The Housing Assistance Supply Experiment found no evidence that introducing the voucher program to a city at scale increased rents (Lowry 1982), though some more recent evidence is contradictory (Susin 2002). Perhaps the best evidence for the voucher program argues that expansion of the voucher program had no effect on prices overall but did increase prices in markets with inelastic supply and for units in the quality range targeted by the program (Eriksen and Ross 2015). However, 
the literature has not studied how recent, large expansions in rapid re-housing vouchers, HUD-VASH vouchers, and permanent supportive housing affect market rents.

Other interventions may impose costs on landlords, unintentionally raising the cost of housing or reducing the number of available units. The classic example of this effect is the market response to rent control. The concern is that lower rents reduce profitability of renting a unit, leading to reduced housing supply in various ways: less new construction, condo conversion, and less investment in maintenance. A wellestablished (e.g., Olsen 1972; Early and Olsen 1998) and active (e.g., Diamond et al. 2018) literature measures the unintended consequences of rent control for landlord behavior and weighs those against the intended effects. Such effects could exist for interventions targeted at homelessness and housing stability. For example, New York City is implementing universal access to legal services in eviction court. As noted above, there is some rigorous evidence that providing legal assistance helps the tenant receiving services (Seron et al. 2001; Greiner et al. 2013). However, such an intervention may hurt other tenants if housing supply contracts because universal legal representation reduces the profitability of renting a unit. While theoretically plausible, such market-level effects have been investigated little in the empirical literature.

Homelessness interventions could also lead to migration across markets. Variation in homelessness programs across space could induce migration from places with less generous programs to those with more generous programs. A large literature posits such effects for a wide variety of public services (cf. McKinnish 2005). In the homelessness context, most expenditures are organized locally such that the generosity of homelessness services varies with local preferences and between urban and rural areas. If migration is significant, local increases in funding might actually increase the local homeless population. Popov (2017) provides evidence that families, but not individuals, experiencing homelessness migrate to locations with more generous homelessness spending. This provides one useful study, though it is typically difficult to track homeless individuals across jurisdictions, which has limited work on this topic. 


\section{References:}

Aidala, Angela A., William McAllister, Maiko Yomogida, and Virginia Shubert. 2013. Frequent Users Service Enhancement "FUSE" Initiative. New York City FUSE II Evaluation Report. New York, NY:

Columbia University Mailman School of Public Health.

Aliprantis, Dionissi, Hal Martin, and David Phillips. "Can Landlords Be Paid to Stop Avoiding Voucher Tenants?” Working Paper, January 2019.

Athey, Susan, and Guido Imbens. 2016. "Recursive Partitioning for Heterogeneous Causal Effects." PNAS 113 (27): 7353-60. https://doi.org/10.1073/pnas.1510489113.

Aubry, Tim, Geoffrey Nelson, and Sam Tsemberis. 2015. "Housing First for People with Severe Mental Illness Who are Homeless: A Review of the Research and Findings from the at Home-Chez Soi Demonstration Project." The Canadian Journal of Psychiatry 60 (11): 467-474. https://doi.org/10.1177/070674371506001102.

Bardine, Darla. 2015. "Over 400 Organizations Support the Homeless Children and Youth Act-NN4Y is One of Them." National Network for Youth. Accessed May 1, 2019. https://www.nn4youth.org/2015/06/03/over-350-organizations-support-the-homeless-childrenand-youth-act-nn4y-is-one-of-them/.

Barrow, Susan M., Daniel B. Herman, Pilar Córdova, and Elmer L. Struening. 1999. "Mortality Among Homeless Shelter Residents in New York City." American Journal Public of Health 89 (4): 529-534. https://doi.org/10.2105/AJPH.89.4.529.

Basu, Anirban, Romina Kee, David Buchanan, and Laura S. Sadowski. 2012. "Comparative Cost Analysis of Housing and Case Management Program for Chronically Ill Homeless Adults Compared to Usual Care." Health Services Research 47 (1): 523-543. https://doi.org/10.1111/i.1475-6773.2011.01350.x.

Burt, Martha, Carol Wilkins, Brooke Spellman, Tracy D’Alanno, Matt White, Meghan Henry, and Natalie Matthews. 2016. Rapid Re-Housing for Homeless Families Demonstration Programs Evaluation Report Part I: How They Worked-Process Evaluation. United Stated Department of Housing and Urban Development, Office of Policy Development and Research.

Byrne, Thomas, Dan Treglia, Dennis P. Culhane, John Kuhn, and Vincent Kane. 2015. "Predictors of Homelessness Among Families and Single Adults After Exit From Homelessness Prevention and Rapid Re-Housing Programs: Evidence From the Department of Veterans Affairs Supportive Services for Veteran Families Program." Housing Policy Debate 26 (1): 252-275. https://doi.org/10.1080/10511482.2015.1060249.

Chetty, Raj, Nathaniel Hendren, and Lawrence F. Katz. 2016. "The Effects of Exposure to Better Neighborhoods on Children: New Evidence from the Moving to Opportunity Experiment." American Economic Review 106 (4): 855-902. https://doi.org/10.1257/aer.20150572.

Chung, Timothy E., Agnes Gozdzik, Luis I. Palma Lazgare, Matthew Jo To, Tim Aubry, James Frankish, Stephen W. Hwang, and Vicky Stergiopoulos. 2017. "Housing First for Older Homeless Adults with Mental Illness: A Subgroup Analysis of the At Home/Chez Soi Randomized Controlled Trial." International Journal of Geriatric Psychiatry 33 (1): 85-95. https://doi.org/10.1002/gps.4682.

Chyn, Eric. 2018. "Moved to Opportunity: The Long-Run Effects of Public Housing Demolition on Children." American Economic Review 108 (10): 3028-3056. https://doi.org/10.1257/aer.20161352.

Cisneros, Henry G., and Lora Engdahl, eds. 2009. From Despair to Hope: Hope VI and the New Promise of Public Housing in America's Cities. Brookings Institution Press.

Collinson, Robert, Ingrid Gould Ellen, and Jens Ludwig. 2016. "Low-Income Housing Policy." In Economics of Means-Tested Transfer Programs in the United States, Volume 2. Moffitt.

Collinson, Robert, and Peter Ganong. 2018. "How do Changes in Housing Voucher Design Affect Rent and Neighborhood Quality?” American Economic Journal: Economic Policy 10 (2): 62-89.

https://doi.org/10.1257/pol.20150176.

Collinson, Robert, and David Reed. "The Effects of Evictions on Low-Income Households." Working Paper, December 2018.

Congressional Budget Office. 2015. Federal Housing Assistance for Low-Income Households. 
Corinth, Kevin. 2017. “The Impact of Permanent Supportive Housing on Homeless Populations." Journal of Housing Economics 35 (2017): 69-84. https://doi.org/10.1016/j.jhe.2017.01.006.

Couloute, Lucius. 2018. "Nowhere to Go: Homelessness Among Formerly Incarcerated People" Prison Policy Initiative, August, 2018. https://www.prisonpolicy.org/reports/housing.html.

Crone, Baylee. 2017. "Veterans Affairs Supportive Housing Vouchers." In 2017 Advocates' Guide: A Primer on Federal Affordable Housing \& Community Development Programs. National Low Income Housing Coalition, 220-222.

Cronley, Courtney, Seokjin Jeong, Jaya B. Davis, and Elissa Madden. 2015. "Effects of Homelessness and Child Maltreatment on the Likelihood of Engaging in Property and Violent Crime During Adulthood." Journal of Human Behavior in the Social Environment 25 (3): 192-203. https://doi.org/10.1080/10911359.2014.966219.

Crouse, Joan M. 1986. The Homeless Transient in the Great Depression: New York State, 1929-1941. SUNY Press. Culhane, Dennis P. 2008. “The Cost of Homelessness: A Perspective from the United States.” European Journal of Homelessness 2 (2008): 97-114.

Culhane, Dennis P., Stephen Metraux, and Trevor Hadley. 2002. "Public Service Reductions Associated with Placement of Homeless Persons with Severe Mental Illness in Supportive Housing." Housing Policy Debate 13 (1):107-163. https://doi.org/10.1080/10511482.2002.9521437.

Cunningham, Mary K., Martha Galvez, Claudia L. Aranda, Rob Santos, Doug Wissoker, Alyse Oneto, Rob Pitingolo, and James Crawford. 2018. A Pilot Study of Landlord Acceptance of Housing Choice Vouchers. Accessed January 17, 2019. https://www.urban.org/research/publication/pilot-study-landlordacceptance-housing-choice-vouchers.

Cunningham, Mary K., Sarah Gillespie, and Jacqueline Anderson. 2015. Rapid Re-Housing: What the Research Says. Urban Institute.

Currie, Lauren B., Akim Moniruzzaman, Michelle L. Patterson, and Julian M. Somers. 2014. At Home/Chez Soi Project: Vancouver Site Final Report. Calgary, AB: Mental Health Commission of Canada.

Dear, Michael J., and Jennifer R. Wolch. 1987. Landscapes of Despair: From Deinstitutionalization to Homelessness. Princeton University Press.

DePastino, Todd. 2003. Citizen Hobo: How a Century of Homelessness Shaped America. University of Chicago Press. Desmond, Matthew. 2016. Evicted: Poverty and Profit in the American City. New York: Crown Publishers.

Desmond, Matthew, 2012. "Tipping the Scales in Housing Court." The New York Times, November 29, 2012.

Desmond, Matthew, and Carl Gershenson. 2016. "Housing and Employment Insecurity Among the Working Poor." Social Problems 63 (1):46-67. https:// doi.org/10.1093/socpro/spv025

Diamond, Rebecca, Tim McQuade, and Franklin Qian. "The Effects of Rent Control Expansion on Tenants, Landlords, and Inequality: Evidence from San Francisco.” NBER Working Paper No. 24181, January 2018. https://doi.org/10.3386/w24181

Dougherty, Conor, 2018. "California Lawmakers Kill Housing Bill After Fierce Debate." The New York Times, April 17, 2018.

Early, Dirk W., and Edgar O. Olsen. 1998. "Rent Control and Homelessness." Regional Science and Urban Economics 28 (6):797-816. https://doi.org/10.1016/S0166-0462(98)00034-9.

Eckholm, Erik. 2007. "Surge Seen in Number of Homeless Veterans." The New York Times, November 8, 2007.

Econometrica, Inc. 2016. Evaluation of HUD's Rental Assistance Demonstration: Interim Report. U.S. Department of Housing and Urban Development Office of Policy Development and Research.

Ellen, Ingrid Gould. 2018. "What Do We Know About Housing Choice Vouchers?” Regional Science and Urban Economics. https://doi.org/10.1016/i.regsciurbeco.2018.07.003.

Engler, Russell. 2010. "Connecting Self-Representation to Civil Gideon: What Existing Data Reveal About When Counsel is Most Needed.” Fordham Urban Law Journal 37 (1): 37-92.

Eriksen, Michael D., and Amanda Ross. 2015. "Housing Vouchers and the Price of Rental Housing." American Economic Journal: Economic Policy 7 (3):154-76. https://doi.org/10.1257/pol.20130064.

Evans, William N., Sarah Kroeger, Caroline Palmer, and Emily Pohl. "The Impact of HUD-VASH Vouchers on Veterans' Homelessness.” Working Paper, 2019. 
Evans, William N., James X. Sullivan, and Melanie Wallskog. 2016. "The Impact of Homelessness Prevention Programs on Homelessness.” Science 353 (6300): 694-699. https://doi.org/10.1126/science.aag0833.

Federal Communications Commission. 2000. "Third Report and Order and Order on Reconsideration: The Use of N11 Codes and Other Abbreviated Dialing Arrangements."

Federal Communication Commission. 2001. "The Use of N11 Codes and Other Abbreviated Dialing Arrangements.” Federal Register. Accessed, January 17, 2019.

https://www.federalregister.gov/documents/2001/02/09/01-3324/the-use-of-n11-codes-andother-abbreviated-dialing-arrangements.

Finkel, Meryl, Meghan Henry, Natalie Matthews, and Brooke Spellman. 2016. Rapid Re-Housing Homeless for Families Demonstration Programs Evaluation Report Part II: Demonstration Findings-Outcomes Evaluation.

U.S. Department of Housing and Urban Development Office of Policy Development and Research.

Flaming, Daniel, Halil Toros, and Patrick Burns. 2015. "The Cost of Homelessness in Silicon Valley." Economic Roundtable, May 2 26, 2015.

Freeman, Lance. 2012. “The Impact of Source Income Laws on Voucher Utilization.” Housing Policy Debate 22 (20): 297-318. https://doi.org/10.1080/10511482.2011.648210.

Freeman, Lance, and Yunjing Li. 2014. "Do Source of Income Anti-Discrimination Laws Facilitate Access to Less Disadvantaged Neighborhoods?” Housing Studies 29 (1): 88-107. https://doi.org/10.1080/02673037.2013.824559.

Gabrielian, Sonya, Anita H. Yuan, Ronald M. Andersen, and Lillian Gelberg. 2016. "Diagnoses Treated in Ambulatory Care Among Homeless-Experienced Veterans: Does Supported Housing Matter?” Journal of Primary Care \& Community Health 7 (4): 281-287. https://doi.org/10.1177/2150131916656009.

Garboden, Philip M.E., Eva Rosen, Stefanie DeLuca, and Kathryn Edin. 2018. “Taking Stock: What Drives Landlord Participation in the Housing Choice Voucher Program.” Housing Policy Debate 28 (6): 979_ 1003. https://doi.org/10.1080/10511482.2018.1502202.

Glaeser, Edward L., Joseph Gyourko, and Raven Saks. 2005. "Why is Manhattan So Expensive? Regulation and the Rise in House Prices" Journal of Law and Economics 48 (2): 331-369. https://doi.org/10.1086/429979.

Glaeser, Edward L., Joseph Gyourko, and Raven E. Saks. 2005. "Why Have Housing Prices Gone Up?” American Economic Review 95 (2): 329-333. https://doi.org/10.1257/0002828057746669961.

Goering, Paula, Scott Veldhuizen, Aimee Watson, Carol Adair, Brianna Kopp, Eric Latimer, Geoff Nelson, Eric MacNaughton, and David Streiner. 2014. National At Home/Chez Soi Final Report. Calgary, AB: Mental Health Commission of Canada.

Goering, Paula, and Aimee Watson. 2012. Beyond Housing: At Home/Chez Soi Early Findings Report. Calgary, AB: Mental Health Commission of Canada.

Goering, Paula N., David L. Streiner, Carol Adair, Tim Aubry, Jayne Barker, Jino Distasio, Stephen W Hwang, Janina Komaroff, Eric Latimer, Julian Somers, and Denise M. Zabkiewicz. 2011. "The At Home/Chez Soi Trial Protocol: A Pragmatic, Multi-Site, Randomised Controlled Trial of a Housing First Intervention for Homeless Individuals with Mental Illness in Five Canadian Cities." BMJ Open 1 (2): e000323-e000323. https://doi.org/10.1136/bmjopen-2011-000323.

Goldfinger, Stephen M., Russell K. Schutt, George S. Tolomiczenko, Larry Seidman, Walter E. Penk, Winston Turner, and Brina Caplan. 1999. "Housing Placement and Subsequent Days Homeless Among Formerly Homeless Adults with Mental Illness.” Psychiatric Services 50 (5): 674-679. https://doi.org/10.1176/ps.50.5.674.

Goodman, Sarena, Peter Messeri, and Brendan O'Flaherty. 2016. "Homelessness Prevention in New York City: On Average, It Works. Journal of Housing Economics 31 (2016): 14-34. https://doi.org/10.1016/j.jhe.2015.12.001.

Greenwood, Roni Michelle, Nicole J. Schaefer-McDaniel, Gary Winkel, and Sam J. Tsemberis. 2005. "Decreasing Psychiatric Symptoms by Increasing Choice in Services for Adults with Histories of Homelessness.” American Journal of Community Psychology 36 (3-4): 223-238. https://doi.org/10.1007/s10464-005-8617-z. 
Greiner, D. James, Cassandra Wolos Pattanayak, and Jonathan Philip Hennessy. 2012. "How Effective Are Limited Legal Assistance Programs? A Randomized Experiment in a Massachusetts Housing Court." Mimeo. https://doi.org/10.2139/ssrn.1880078

Greiner, D. James, Cassandra Wolos Pattanayak, and Jonathan Hennessy. 2013. “The Limits of Unbundled Legal Assistance: A Randomized Study in a Massachusetts District Court and Prospects for the Future." Harvard Law Review 126 (4): 901-981.

Gubits, Daniel, Marybeth Shinn, Stephen Bell, Michelle Wood, Samuel R. Dastrup, Claudia Solari, Scott Brown, Steven Brown, Lauren Dunton, Winston Lin, Debi McInnis, Jason Rodriguez, Galen Savidge, and Brooke Spellman. 2015. Family Options Study: Short-Term Impacts of Housing and Services Interventions for Homeless Families. U.S. Department of Housing and Urban Development Office of Policy Development and Research. https://doi.org/10.2139/ssrn.3055272.

Gubits, Daniel, Marybeth Shinn, Michelle Wood, Stephen Bell, Samuel Dastrup, Claudia Solari, Scott Brown, Debi McInnis, Tom McCall, and Utsav Kattel. 2016. "Family Options Study: 3-Year Impacts of Housing and Services Interventions for Homeless Families." Mimeo. https://doi.org/10.2139/ssrn.3055295.

Gubits, Daniel, Marybeth Shinn, Michelle Wood, Scott R. Brown, Samuel R. Dastrup, and Stephen H. Bell. 2018. "What Interventions Work Best for Families Who Experience Homelessness? Impact Estimates from the Family Options Study.” Journal of Policy Analysis and Management 37 (4): 835-866. https://doi.org/10.1002/pam.22071.

Gubits, Daniel, Brooke Spellman, Lauren Dunton, Scott Brown, Michelle Wood, Stephen Bell, and Marybeth Shinn. 2013. Family Options Study-Interim Report. U.S. Department of Housing and Urban Development Office of Policy Development and Research.

Gulcur, Leyla, Ana Stefancic, Marybeth Shinn, Sam Tsemberis, and Sean N. Fischer. 2003. "Housing, Hospitalization, and Cost Outcomes for Homeless Individuals with Psychiatric Disabilities Participating in Continuum of Care and Housing First Programmes." Journal of Community \& Applied Social Psychology 13 (2): 171-186. https://doi.org/10.1002/casp.723.

Gyourko, Joseph, Christopher Mayer, and Todd Sinai. 2013. "Superstar Cities." American Economic Journal: Economic Policy 5 (4): 167-199. https://doi.org/10.1257/pol.5.4.167.

Henry, Meghan, Rian Watt, Lily Rosenthal, and Azim Shivji. 2017. The 2017 Annual Homeless Assessment Report (AHAR) to Congress. U.S. Department of Housing and Urban Development Office of Community Planning and Development.

Herman, Daniel B., Sarah Conover, Prakash Gorroochurn, Kinjia Hinterland, Lori Hoepner, and Ezra S. Susser. 2011. "Randomized Trial of Critical Time Intervention to Prevent Homelessness After Hospital Discharge." Psychiatric Services 62 (7): 713-719.

https://doi.org/10.1176/ps.62.7.pss6207 0713.

Hopper, Kim, Marybeth Shinn, Eugene Laska, Morris Meisner, and Joseph Wanderling. 2008. "Estimating Numbers of Unsheltered Homeless People Through Plant-Capture and Postcount Survey Methods." American Journal of Public Health 98 (8): 1438-1442. https://doi.org/10.2105/AJPH.2005.083600.

Humphires, John Eric, Nick Mader, Daniel Tannenbaum, and Winnie van Dijk. "Does Eviction Cause Poverty? Quasi-Experimental Evidence from Cook County, IL.” Working Paper, December 2018.

Hurlburt, Michael S., Hough, Richard L., and Wood, P.A. 1996. "Effects of Substance Abuse on Housing Stability of Homeless Mentally Ill Persons in Supported Housing.” Psychiatric Services 47 (7): 731-736. https://doi.org/10.1176/ps.47.7.731.

Hwang, Stephen W., Vicky Stergiopoulos, Patricia O’Campo, and Agnes Gozdzik. 2012. “Ending Homelessness Among People with Mental Illness: The At Home/Chez Soi Randomized Trial of a Housing First Intervention in Toronto.” BMC Public Health 12 (1):787. https://doi.org/10.1186/1471-2458-12-787.

Jacob, Brian A., Max Kapustin, and Jens Ludwig. 2015. "The Impact of Housing Assistance on Child Outcomes: Evidence from a Randomized Housing Lottery." The Quarterly Journal of Economics 130 (1): 465-506. https://doi.org/10.1093/qje/qju030. 
Jacob, Brian A., and Jens Ludwig. 2012. "The Effects of Housing Assistance on Labor Supply: Evidence from a Voucher Lottery." American Economic Review 102 (1): 272-304.

https://doi.org/10.1257/aer.102.1.272.

Johnson, Corey, and Stephen Levin. 2018. Report of the Finance Division on the Fiscal 2019 Preliminary Budget and the Fiscal 2018 Preliminary Mayor's Management Report for the Department of Homelessness Services. The Council of the City of New York Department of Homeless Services.

Joint Center for Housing Studies, 2018. The State of the Nation's Housing. Harvard University.

Kertesz, Stefan G., Ashley N. Mullins, Joseph E. Schumacher, Dennis Wallace, Katharine Kirk, and Jesse B. Milby. 2007. "Long-Term Housing and Work Outcomes Among Treated Cocaine-Dependent Homeless Persons." The Journal of Behavioral Health Services \& Research 34 (1): 17-33. https://doi.org/10.1007/s11414-006-9041-3.

Kingsley, G. Thomas. 2017. Trends in Housing Problems and Federal Housing Assistance. The Urban Institute.

Kirst, Maritt, Suzanne Zerger, Vachan Misir, Stephen Hwang, and Vicky Stergiopoulos. 2015. "The Impact of a Housing First Randomized Controlled Trial on Substance Use Problems Among Homeless Individuals with Mental Illness." Drug and Alcohol Dependence 146 (1): 24-29. https://doi.org/10.1016/i.drugalcdep.2014.10.019.

Kling, Jeffrey R., Jeffrey B. Liebman, and Lawrence F. Katz. 2007. "Experimental Analysis of Neighborhood Effects." Econometrica 75 (1): 83-119. https://doi.org/10.1111/i.1468-0262.2007.00733.x.

Kusmer, Kenneth L. 2002. Down and Out, on the Road: The Homeless in American History. Oxford University Press.

Laska, Eugene M., and Morris Meisner. 1993. “A Plant-Capture Method for Estimating the Size of a Population from a Single Sample.” Biometrics 49 (1) 209-220. http://dx/doi.org/10.2307/2532614.

Lowry, Ira S. 1982. Experimenting with Housing Allowances: Executive Summary [of] the Final Comprehensive Report of the Housing Assistance Supply Experiment, Sponsored by the Office of Policy Development and Research, U.S. Department of Housing and Urban Development. Rand Corporation.

Lucas, David S. 2017. “The Impact of Federal Homelessness Funding on Homelessness" Southern Economic Journal 84 (2): 548-576. https://doi.org/10.1002/soej.12231.

Mares, Alvin S., and Robert A. Rosenheck. 2011. "A Comparison of Treatment Outcomes Among Chronically Homelessness Adults Receiving Comprehensive Housing and Health Care Services Versus Usual Local Care." Administration and Policy in Mental Health and Mental Health Services Research 38 (6): 459-475. https://doi.org/10.1007/s10488-011-0333-4.

McCandless, Lawrence C., Michelle L. Patterson, Lauren B. Currie, Akm Moniruzzaman, and Julian M. Somers. 2016. "Bayesian Estimation of the Size of a Street-Dwelling Homeless Population." Journal of Modern Applied Statistical Methods 15 (1): 276-298. https://doi.org/10.22237/jmasm/1462076040.

McCarty, Maggie, Libby Perl, and Katie Jones. 2014. Overview of Federal Housing Assistance Programs and Policy. Congressional Research Service. Updated March 27, 2019.

McKinnish, Terra. 2005. "Importing the Poor: Welfare Magnetism and Cross-Border Welfare Migration." The Journal of Human Resources 15 (2): 57-76. https://doi.org/10.3368/ihr.XL.1.57.

Milby, Jesse B., Joseph E. Schumacher, Dennis Wallace, Michelle J. Freedman, and Rudy E. Vuchinich. 2005. "To House or Not to House: The Effects of Providing Housing to Homeless Substance Abusers in Treatment." American Journal of Public Health 95 (7) 1259-1265. https://doi.org/10.2105/AJPH.2004.039743

Mills, Gregory, Daniel Gubits, Larry Orr, David Long, Judie Feins, Bulbul Kaul, and Michelle Wood. 2006. Effects of Housing Vouchers on Welfare Families. U.S. Department of Housing and Urban Development Office of Policy Development and Research.

Montgomery, Ann Elizabeth, and Megan Cusack. 2017. HUD-VASH Exit Study Final Report. U.S. Department of Housing and Urban Development Office of Policy Development and Research.

Montgomery, Ann Elizabeth, Lindsay L. Hill, Vincent Kane, and Dennis P. Culhane. 2013. "Housing Chronically Homeless Veterans: Evaluating the Efficacy of a Housing First Approach to HUDVASH.” Journal of Community Psychology 41 (4): 505-514. https:// doi.org/10.1002/jcop.21554.

Moore, Mary Frances Kathleen. "Rental Market Discrimination \& the Housing Choice Voucher Program." Working Paper. 
Mykyta, Laryssa, and Suzanne Macartney. "The Effects of Recession on Household Composition: "Doubling Up” and Economic Well-Being." SEHSD Working Paper No. 2011-4, April 2011.

Mykyta, Laryssa, and Natasha Pilkauskas. "Household Composition and Family Wellbeing: Exploring the Relationship Between Doubling Up and Hardship." SEHSD Working Paper No. 2016-10, March 2016.

National Academies of Sciences, Engineering, and Medicine 2018. Permanent Supportive Housing: Evaluating the Evidence for Improving Health Outcomes Among People Experiencing Chronic Homelessness. Washington, DC: The National Academies Press. https://doi.org/10.17226/25133

National Alliance to End Homelessness. 2015. "Opposition Statement to the Homeless Children and Youth Act.” Accessed May 1, 2019. https://endhomelessness.org/resource/opposition-statement-tohomeless-children-and-youth-act/.

National Alliance to End Homelessness. 2014. "Rapid Re-Housing: A History and Core Components." Accessed May 1, 2019. https://endhomelessness.org/resource/rapid-re-housing-a-history-and-corecomponents/.

National Center for Homeless Education. n.d. "The McKinney-Vento Definition of Homeless.” Accessed June 10, 2019. https://nche.ed.gov/mckinney-vento-definition/.

National Homeless Information Project. n.d. "HUD VASH Costs by PHA December 2016." Accessed December 13, 2018.

New York State Division of Housing and Community Renewal Office of Rent Administration. 2018. "Fact Sheet: \#1 Rent Stabilization and Rent Control.” Accessed January 17, 2019. http://www.nyshcr.org/Rent/FactSheets/orafac1.pdf.

O'Connell, Maria J., Wesley J. Kasprow, and Robert A. Rosenheck. 2012. "Differential Impact of Supported Housing on Selected Subgroups of Homeless Veterans With Substance Abuse Histories." Psychiatric Services 63 (12): 1195-1205. https://doi.org/10.1176/appi.ps.201000229.

O’Flaherty, Brendan. 2019. "Homelessness Research: A Guide for Economists (and Friends)." Journal of Housing Economics 44 (2019): 1-25. https://doi.org/10.1016/j.jhe.2019.01.003.

Olsen, Edgar O. 1972. “An Econometric Analysis of Rent Control.” Journal of Political Economy 80 (6): 1081 1100.

Olsen, Edgar O., and Jeffrey E. Zabel. 2015. "Chapter 14-US Housing Policy.” In Handbook of Regional and Urban Economics 5(2015): 887-986. https://doi.org/10.1016/B978-0-444-59531-7.00014-4.

Padgett, Deborah K., Leyla Gulcur, and Sam Tsemberis. 2006. "Housing First Services for People Who Are Homeless With Co-Occurring Serious Mental Illness and Substance Abuse." Research on Social Work Practice 16 (1): 74-83. https://doi.org/10.1177/1049731505282593.

Palmer, Caroline, David C. Phillips, and James X. Sullivan. 2019. "Does Emergency Financial Assistance Reduce Crime?” Journal of Public Economics 169 (2019) 31-51.

Pearson, Carol L., Gretchen Locke, Ann Elizabeth Montgomery, and Larry Buron. 2007. The Applicability of Housing First Models to Homeless Persons with Serious Mental Illness. U.S. Department of Housing and Urban Development Office of Policy Development and Research.

Perl, Libby, and Maggie McCarty. "Income Eligibility and Rent in HUD Rental Assistance Programs: Frequently Asked Questions” 2015. Congressional Research Service. Updated March 28, 2017. https://www.everycrsreport.com/reports/R42734.html.

Peters, Mark. 1990. "Homelessness: A Historical Perspective on Modern Legislation.” Michigan Law Review 88 (5) 1209-1244. https://doi.org/10.2307/1289121.

Phillips, David. 2017. "Landlords Avoid Tenants Who Pay with Vouchers." Economics Letters 151 (C): 48-52. Phillips, David. "Measuring Housing Stability with Consumer Reference Data." Working Paper, April 2019.

Pilkauskas, Natasha, Irwin Garfinkel, and Sara S. McLanahan. 2014. "The Prevalence and Economic Value of Doubling Up.” Demography 51 (5): 1667-76. https://doi.org/10.1007/s13524-014-0327-4.

Popov, Igor. "Homeless Programs and Social Insurance." Working Paper, November 2017.

Quigley, John M., Steven Raphael, and Eugene Smolensky. 2001. Homeless in America, Homeless in California. Review of Economics and Statistics 83 (1): 37-51. https://doi.org/10.1162/003465301750160027. 
Raphael, Steven. 2010. "Housing Market Regulation and Homelessness." In How to House the Homeless. New York, NY: Russell Sage Foundation.

Rodriguez, Jason M., and Tessa A. Eidelman. 2017. "Homelessness Interventions in Georgia: Rapid ReHousing, Transitional Housing, and the Likelihood of Returning to Shelter." Housing Policy Debate 27 (6): 825-842. https://doi.org/10.1080/10511482.2017.1313292.

Rolston, Howard, Judy Geyer, and Gretchen Locke. 2013. Evaluation of the Homebase Community Prevention Program. Abt Associates.

Rosen, Eva. 2014. "Rigging the Rules of the Game: How Landlords Geographically Sort Low-Income Renters." City \& Community 13 (4): 310-340. https://doi.org/10.1111/cico.12087.

Rosenheck, Robert, Wesley Kasprow, Linda Frisman, and Wen Liu-Mares. 2003. "Cost-Effectiveness of Supported Housing for Homeless Persons with Mental Illness.” Archives of General Psychiatry 60 (9): 940-951. https://doi.org/10.1001/archpsyc.60.9.940.

Rossi, Peter. 1990. "The Old Homeless and the New Homeless in Historical Perspective." American Psychologist 45 (8): 954-959.

Saiz, Albert. 2010. “The Geographic Determinants of Housing Supply.” The Quarterly Journal of Economics 125 (3): 1253-1296. https://doi.org/10.1162/qjec.2010.125.3.1253.

Samuels, Judith, Patrick J. Fowler, Andrea Ault-Brutus, Dei-In Tang, and Katherine Marcal. 2015. “TimeLimited Case Management for Homeless Mothers With Mental Health Problems: Effects on Maternal Mental Health." Journal of the Society for Social Work and Research 6 (4): 515-539. https://doi.org/10.1086/684122.

Sanbonmatsu, Lisa, Jens Ludwig, Lawrence F. Katz, Lisa A. Gennetian, Greg J. Duncan, Ronald C. Kessler, Emma Adam, Thomas W. McDade, and Stacy Tessler Lindau. 2011. Moving to Opportunity for Fair Housing Demonstration Program — Final Impacts Evaluation. U.S. Department of Housing and Urban Development Office of Policy Development and Research.

Schumbert, Herman Jacob Paul. 1935. Twenty Thousand Transients: A One Year's Sample of those Who Apply for Aid in a Northern City. Buffalo, NY: Emergency Relief Bureau.

Seron, Carroll, Martin Frankel, Gregg Van Ryzin, and Jean Kovath. 2001. “The Impact of Legal Counsel on Outcomes for Poor Tenants in New York City's Housing Court: Results of a Randomized Experiment." Law \& Society Review 35 (2): 419-434. https://doi.org/10.2307/3185408.

Shaw, Ian, Michael Bloor, Richard Cormack, and Howard Williamson. 1996. "Estimating the Prevalence of Hard-to-Reach Populations: The Illustration of Mark-Recapture Methods in the Study of Homelessness." Social Policy and Administration 30 (1): 69-85. https://doi.org/10.1111/j.14679515.1996.tb00482.x.

Shinn, Marybeth, Andrew L. Greer, Jay Bainbridge, Jonthan Kwon, and Sara Zuiderveen. 2013. "Efficient Targeting of Homelessness Prevention Services for Families." American Journal of Public Health 103 (2013): S324-S30. https://dx.doi.org/10.2105\%2FAJPH.2013.301468.

Shinn, Marybeth, Judith Samuels, Sean N. Fischer, Amanda Thompkins, and Patrick J. Fowler. 2015. "Longitudinal Impact of a Family Critical Time Intervention on Children in High-Risk Families Experiencing Homelessness: A Randomized Trial." American Journal of Community Psychology 56 (3-4): 205-216. https://doi.org/10.1007/s10464-015-9742-y.

Snow, David A., Susan G. Baker, and Leon Anderson. 1989. "Criminality and Homeless Men: An Empirical Assessment." Social Problems 36 (1): 532-549. https://doi.org/10.2307/3096817.

Snyder, Thomas D., Cristobal de Brey, and Sally A. Dillow. 2018. Digest of Education Statistics 2016. U.S. Department of Education.

Solari, Claudia D., Azim Shivji, Tanya de Sousa, Rian Watt, and Mark Silverbush. 2016. The 2016 Annual Homeless Assessment Report (AHAR) to Congress Part 2: Estimates of Homelessness in the United States. U.S. Department of Housing and Urban Development Office of Community Planning and Development.

Somers, Julian M., Akm Moniruzzaman, Michelle Patterson, Lauren Currie, Stefanie N. Rezansoff, Anita Palepu, and Karen Fryer. 2017. "A Randomized Trial Examining Housing First in Congregate and Scattered Site Formats.” PLOS ONE 12 (1): e0168745. https://doi.org/10.1371/journal.pone.0168745. 
Spellman, Brooke, Jill Khadduri, Brian Sokol, and Josh Leopold. 2010. Costs Associated with First-Time Homelessness for Families and Individuals. U.S. Department of Housing and Urban Development Office of Policy Development and Research.

Spellman, Brooke, Meghan Henry, Meryl Finkel, Natalie Matthews, and Tom McCall. 2014. Brief \#3: Rapid Re-Housing for Homeless Families Demonstration Program: Subsequent Returns to Shelter for All Families Served. U.S. Department of Housing and Urban Development Office of Policy Development and Research.

Stergiopoulos, Vicky, Agnes Gozdzik, Vachan Misir, Anna Skosireva, Jo Connelly, Aseefa Sarang, Adam Whisler, Stephen W. Hwang, Patricia O'Campo, and Kwame McKenzie. 2015. "Effectiveness of Housing First with Intensive Case Management in an Ethnically Diverse Sample of Homeless Adults with Mental Illness: A Randomized Controlled Trial.” PLOS ONE 10 (7): e0130281. https://doi.org/10.1371/journal.pone.0130281.

Stergiopoulos, Vicky, Pat O’Campo, Stephen Hwang, Agnes Gozdzik, Jeyaggobi Jeyaratnam, Vachan Misir, Rosane Nisenbaum, Suzanne Zerger, and Maritt Kirst. 2014. At Home/Chez Soi Project: Toronto Site Final Report. Calgary, AB: Mental Health Commission of Canada.

Susin, Scott. 2002. "Rent Vouchers and the Price of Low-Income Housing." Journal of Public Economics 83 (1): 109-152. https://doi.org/10.1016/S0047-2727(01)00081-0.

Thaden, Emily, and Ruoniu Wang. 2017. "Inclusionary Housing in the United States: Prevalence, Impact, and Practices.” Working Paper, September 2017.

The Urban Institute. 2012. Expanding Housing Opportunities Through Inclusionary Zoning: Lessons from Two Counties. U.S. Department of Housing and Urban Development Office of Policy Development and Research.

Tsemberis, Sam. 1999. "From Streets to Homes: An Innovative Approach to Supported Housing for Homeless Adults with Psychiatric Disabilities." Joumal of Community Psychology 27 (2): 225-241. https://doi.org/10.1002/(SICI)1520-6629(199903)27:2<225::AID-JCOP9>3.0.CO;2-Y.

Tsemberis, Sam, and Sara Asmussen. 1999. "From Streets to Homes: The Pathways to Housing Consumer Preference Supported Housing Model." Alcoholism Treatment Quarterly 17 (1-2): 113-131. https://doi.org/10.1300/J020v17n01 07.

Tsemberis, Sam, and Ronda F. Eisenberg. 2000. "Pathways to Housing: Supported Housing for StreetDwelling Homeless Individuals with Psychiatric Disabilities." Psychiatric Services 51 (4): 487-493. https://doi.org/10.1176/appi.ps.51.4.487.

Tsemberis, Sam, Leyla Gulcur, and Maria Nakae. 2004. "Housing First, Consumer Choice, and Harm Reduction for Homeless Individuals With a Dual Diagnosis." American Journal of Public Health 94 (2004): 651-656. https://doi.org/10.2105/AJPH.94.4.651.

Tuller, David. 2018. "Housing and Health: The Role Of Inclusionary Zoning." Health Affairs, June 7, 2017. U.S. Department of Housing and Urban Development. 2018. "Housing Choice Vouchers Fact Sheet." Accessed December 6, 2018. https://www.hud.gov/program_offices/public indian housing/programs/hcv/about/fact sheet.

U.S. Department of Housing and Urban Development. 2018. "HUD 2018 Continuum of Care Homeless Assistance Programs Housing Inventory Count Report.” Accessed June 24, 2019. https:// files.hudexchange.info/reports/published/CoC HIC NatlTerrDC 2018.pdf.

U.S. Department of Housing and Urban Development. 2018. "Picture of Subsidized Households." Accessed December 6, 2018. https://www.huduser.gov/portal/datasets/assthsg.html\#2009-2017 query.

U.S. Department of Housing and Urban Development. 2017. "Table 3: Characteristics of LIHTC Projects, 1995-2015.” Accessed January 17, 2019. https://www.huduser.gov/portal/Datasets/lihtc/tables9515.pdf.

U.S. Department of Housing and Urban Development. 2007. "Defining Chronic Homeless: A Technical Guide for HUD Programs." HUD Office of Community Planning and Development.

U.S. Department of Housing and Urban Development. n.d. "HUD-VASH Vouchers." https://www.hud.gov/program_offices/public indian_housing/programs/hcv/vash.

U.S. Department of Housing and Urban Development. n.d. "Using Data to Understand and End Homelessness.” Accessed June 1, 2019. https://www.huduser.gov/portal/periodicals/em/summer12/highlight2.html. 
United States Interagency Council on Homelessness. 2018. "U.S. Targeted Homelessness Assistance: Discretionary Budget Authority in Millions of Dollars."

https://www.usich.gov/resources/uploads/asset library/fy2018-budget-enacted-final.pdf.

United Way of Metro Atlanta. n.d. United Way Atlanta 2-1-1 Community Resource Database. Accessed January 17, 2019. http://211online.unitedwayatlanta.org/.

United Way Worldwide. n.d. “About 211.” 211. Accessed January 17, 2019. http://www.211.org/pages/about.

Wiltz, Teresa. 2017. "How Free Legal Help Can Prevent Evictions.” Stateline, Pew Charitable Trusts, October 27, 2017. https://www.pewtrusts.org/en/research-and-analysis/blogs/stateline/2017/10/27/howfree-legal-help-can-prevent-evictions.

Wolitski, Richard J., Daniel P. Kidder, Sherri L. Pals, Scott Royal, Angela Aidala, Ron Stall, David R. Holtgrave, David Harre, and Cari Courtenay-Quirk. 2010. "Randomized Trial of the Effects of Housing Assistance on the Health and Risk Behaviors of Homeless and Unstably Housed People Living with HIV." AIDS and Behavior 14 (3): 493-503. https://doi.org/10.1007/s10461-009-9643-x.

Wood, Michelle, Jennifer Turnham, and Gregory Mills. 2008. "Housing Affordability and Family WellBeing: Results from the Housing Voucher Evaluation.” Housing Policy Debate 19 (2): 367-412. https://doi.org/10.1080/10511482.2008.9521639. 
Figure 1: Homeless PIT Estimates

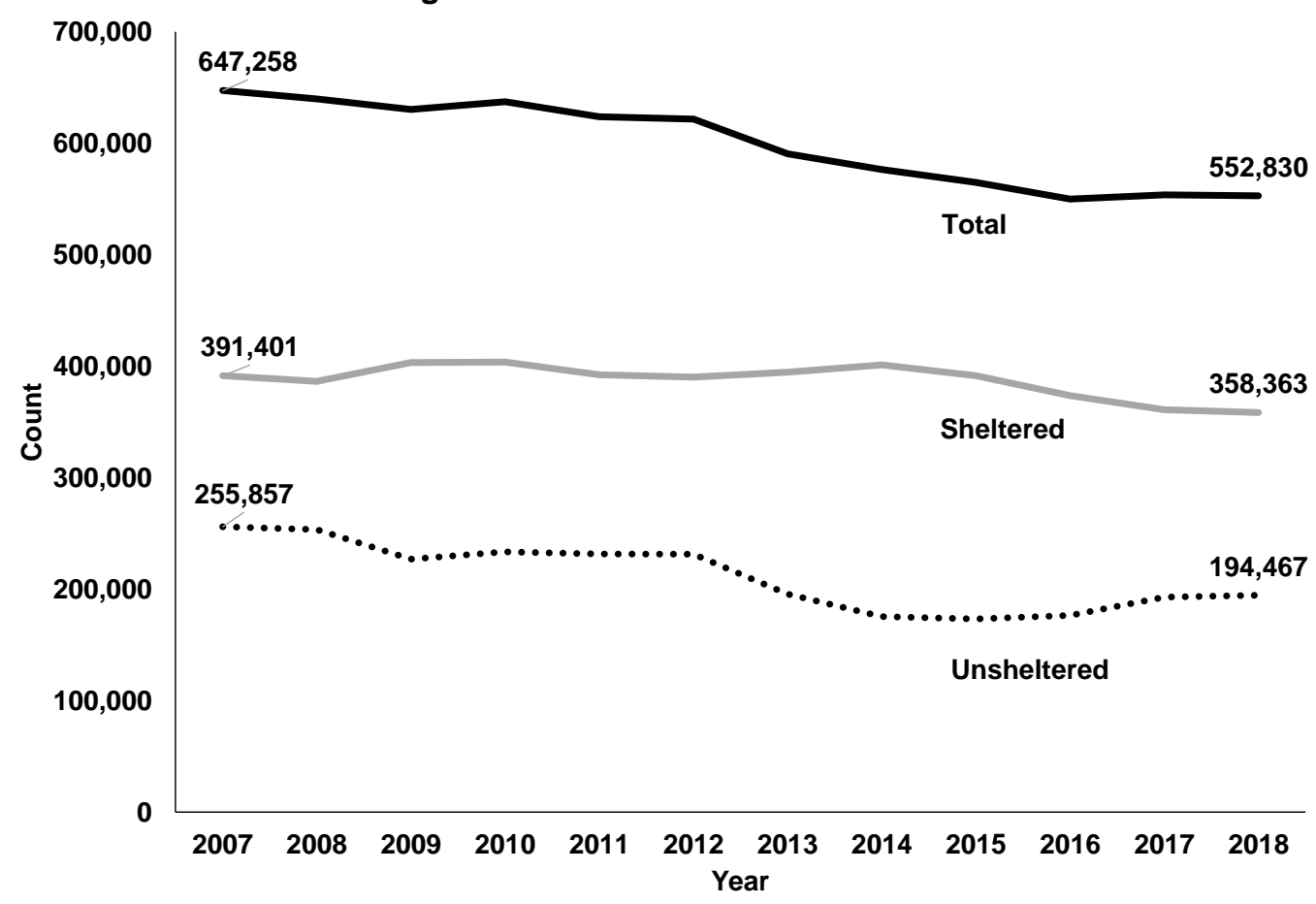

Figure 2: Homeless Counts for Specific Groups

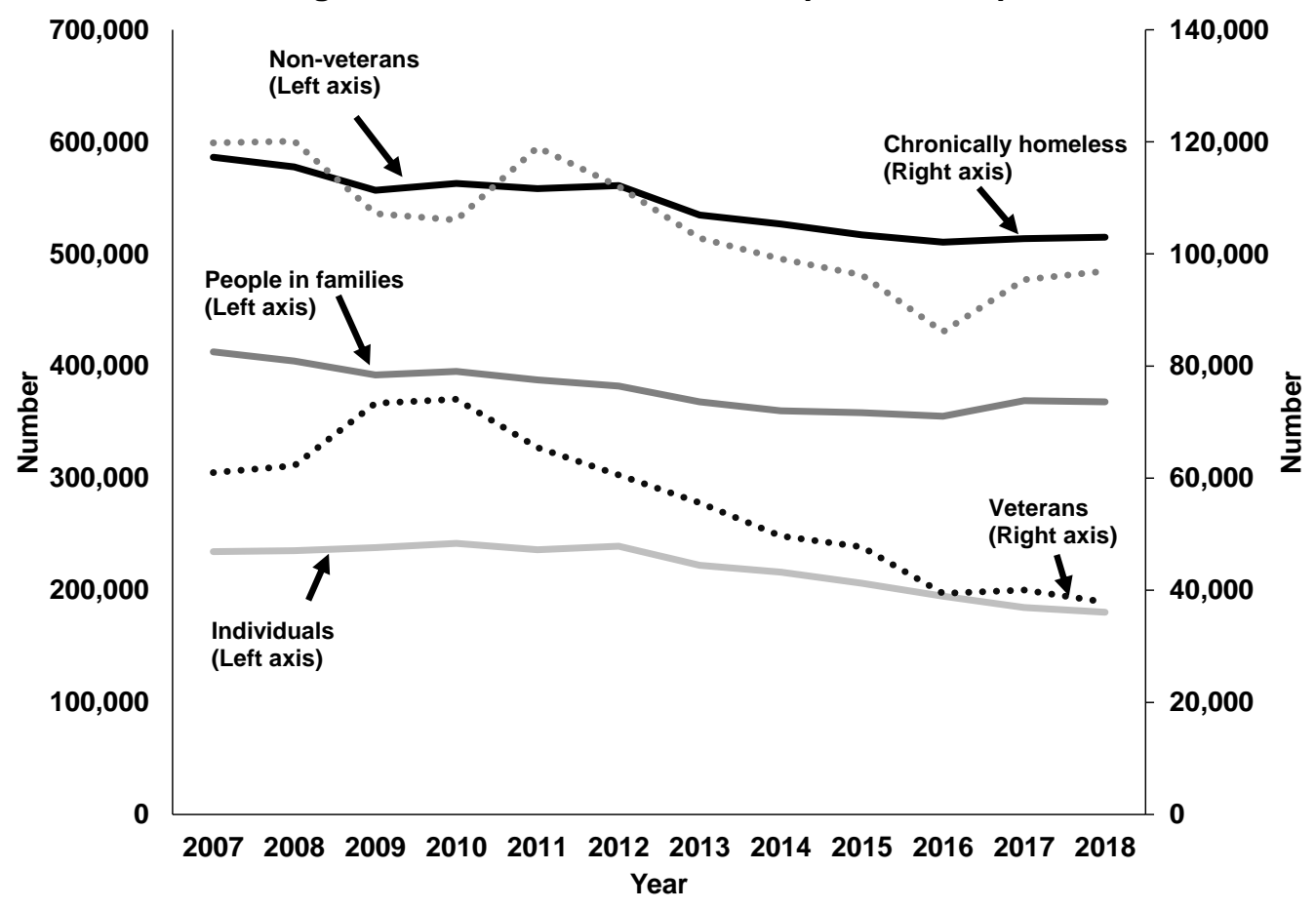


Figure 3: Homelessness Rates from PIT Estimates

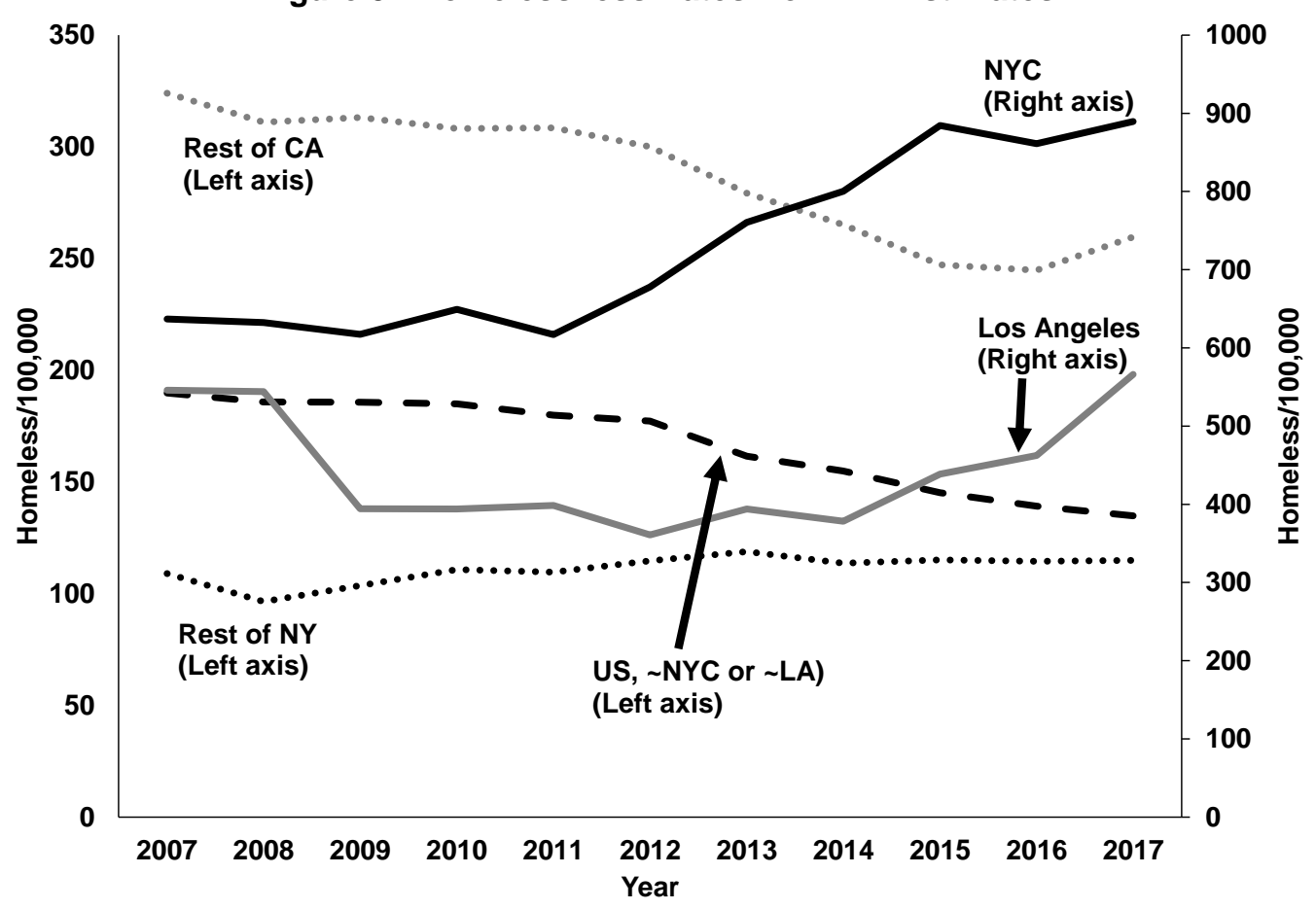

Figure 4: Scatterplot of Median Rent and Homeless Rate (per 100,000), by CoC, 2017

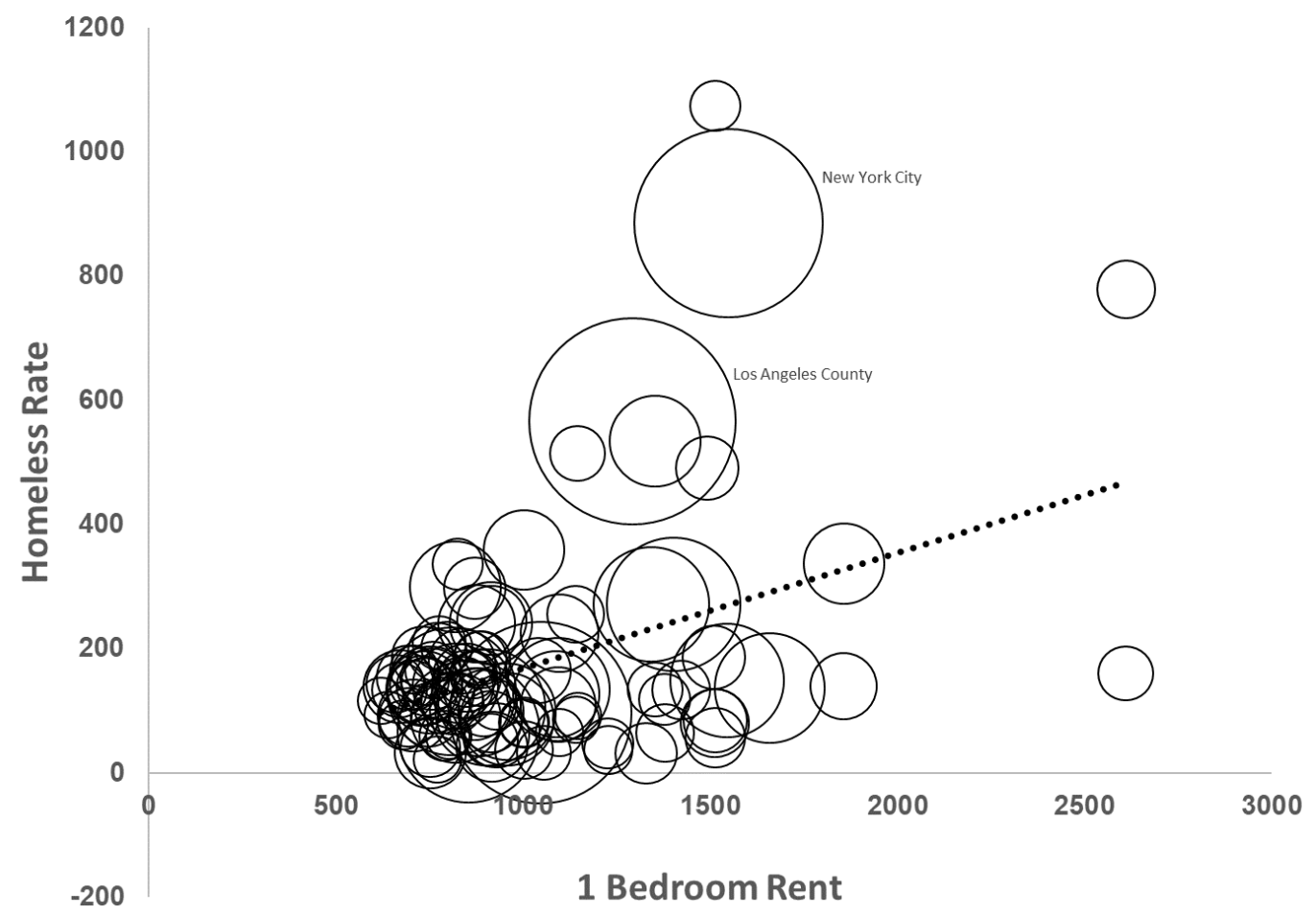


Figure 5: Scatterplot of \% Change in Median Rent and Homeless Rate, by CoC, 2010 to 2017

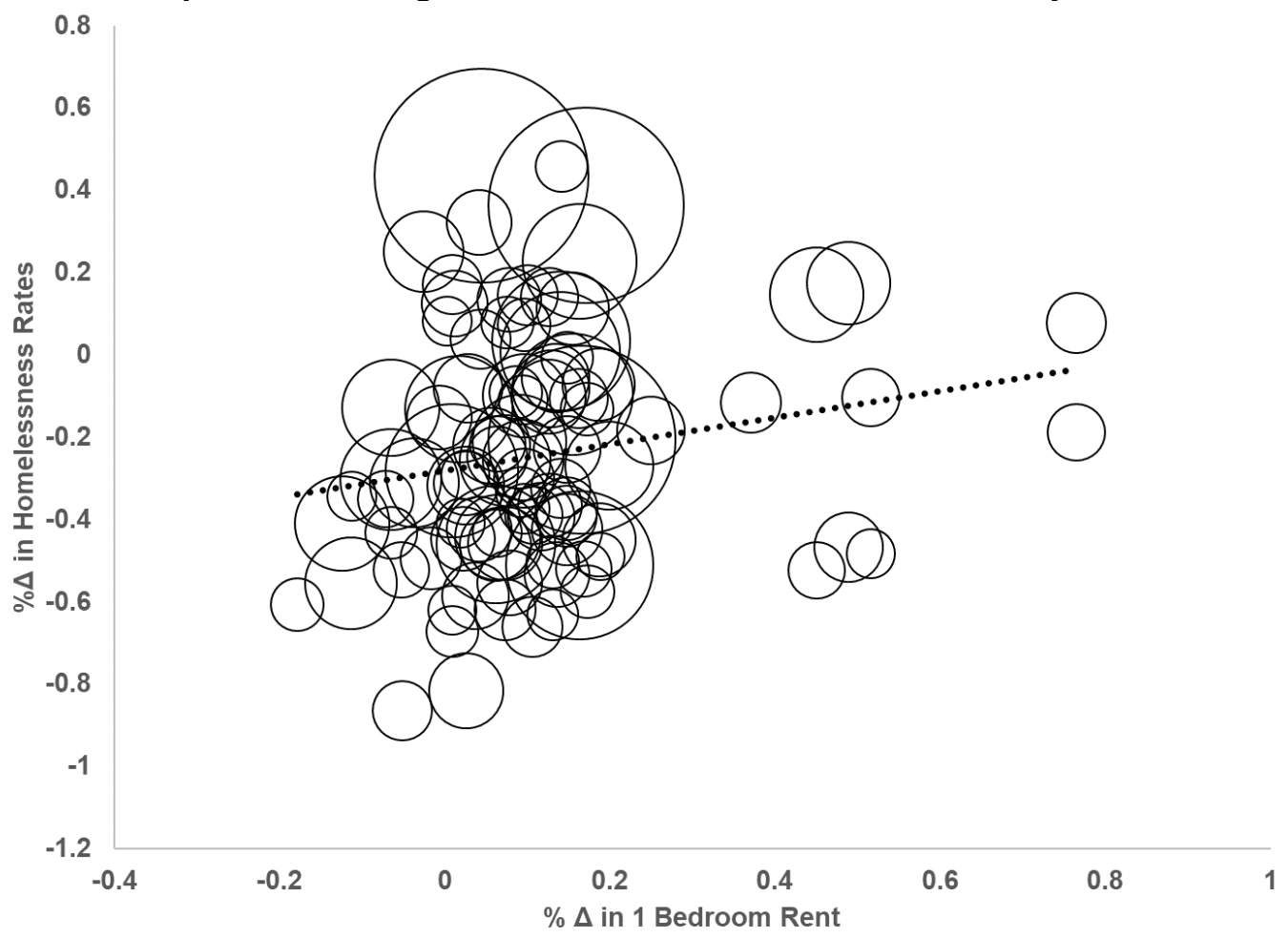

Figure 6: Homeless Counts from the CDD and PIT Estimates

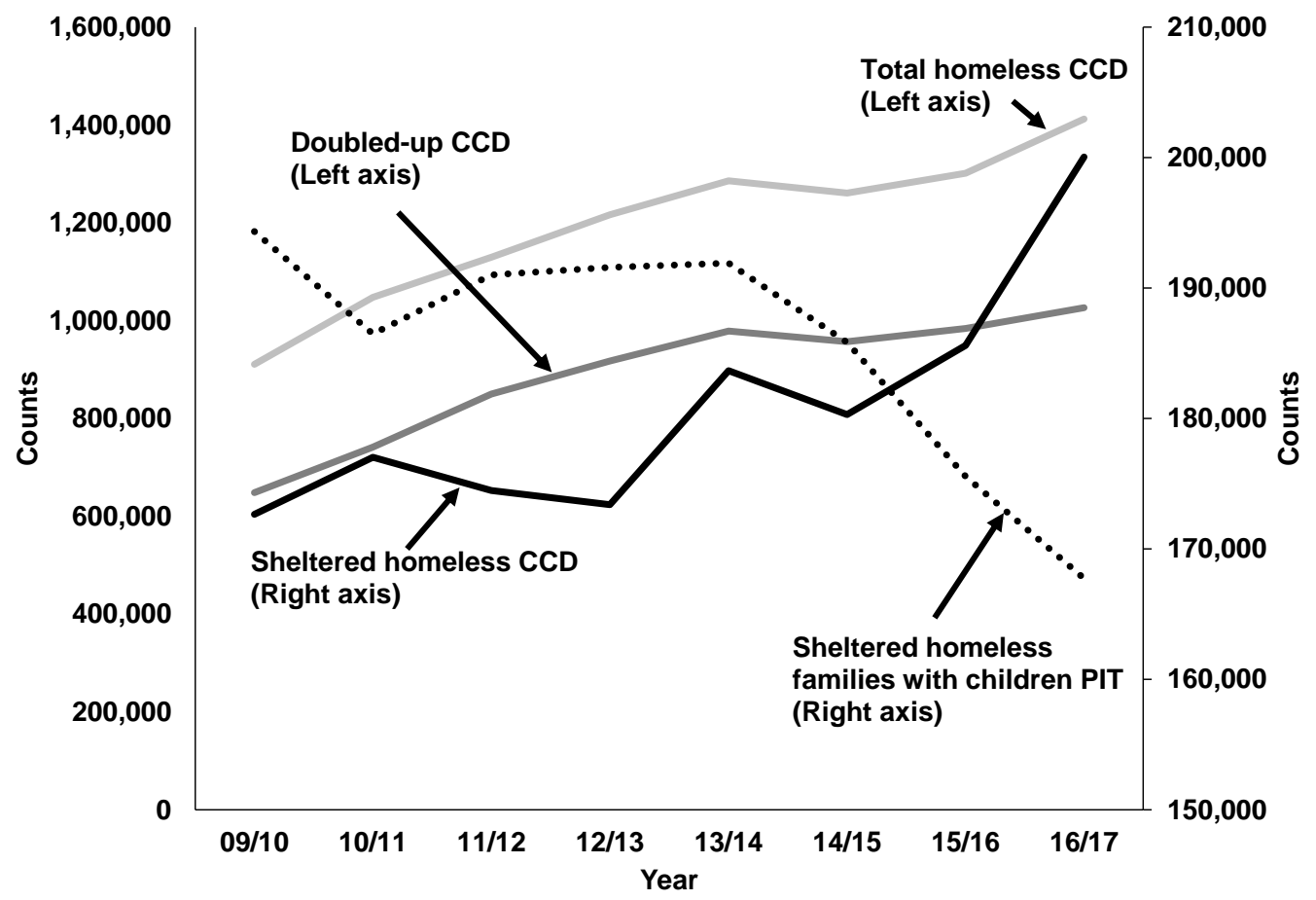


Figure 7: Resources Devoted to the Homeless, HIC

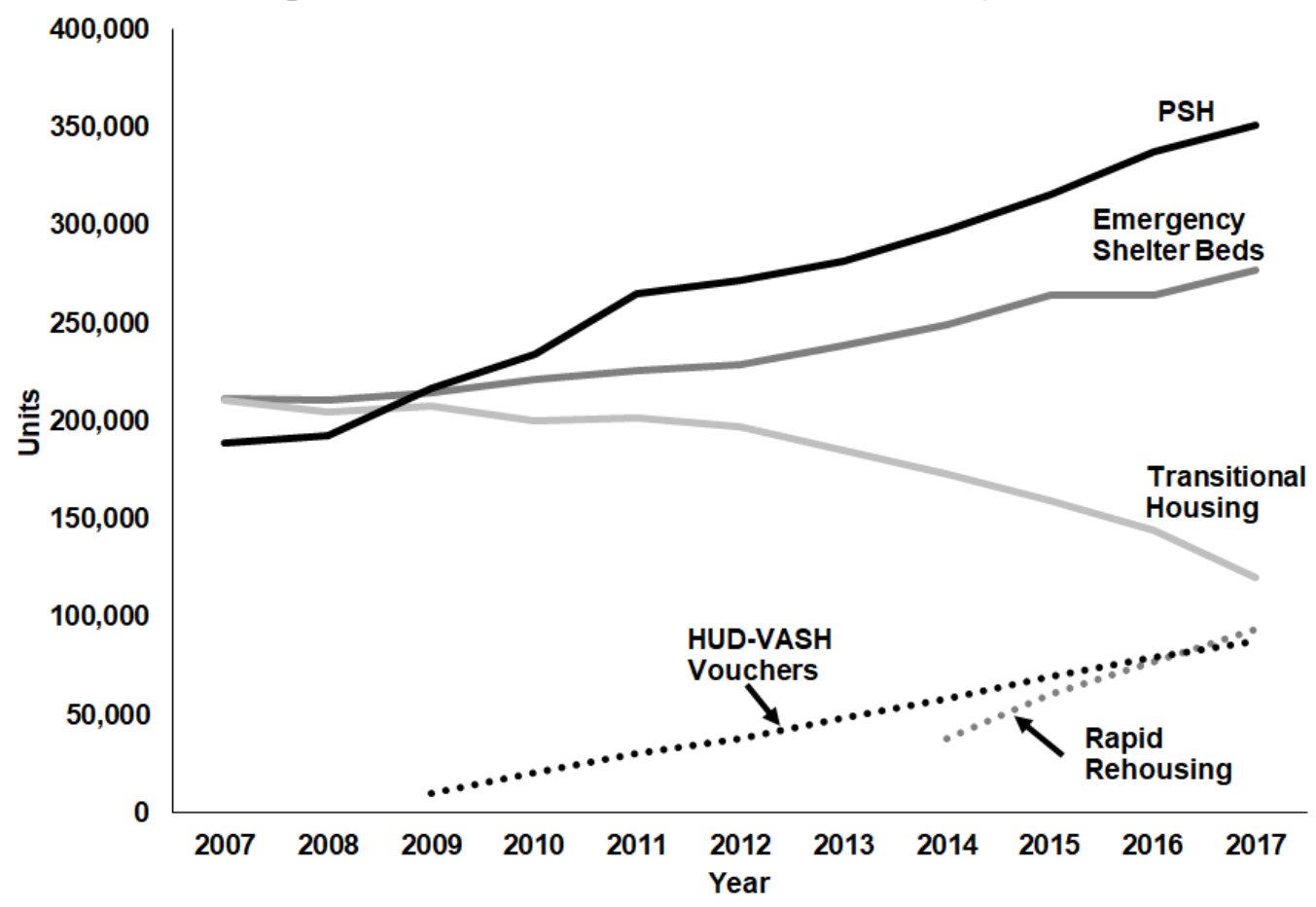


Table 1:

Homelessness Rates by Demographic Characteristics, 2017

\begin{tabular}{|c|c|c|c|c|}
\hline By group & $\begin{array}{r}\text { Homeless/ } \\
100,000\end{array}$ & $\begin{array}{l}\% \text { of } \\
\text { pop. }\end{array}$ & $\begin{array}{r}\% \text { of } \\
\text { homeless }\end{array}$ & $\begin{array}{r}\text { Risk } \\
\text { Ratio }\end{array}$ \\
\hline For the nation & 170.8 & & & \\
\hline \multicolumn{5}{|l|}{ By $\operatorname{sex}^{a}$} \\
\hline Females & 131.3 & $50.8 \%$ & $39.0 \%$ & 0.63 \\
\hline Males & 209.6 & $49.2 \%$ & $60.4 \%$ & 1.60 \\
\hline \multicolumn{5}{|l|}{ By ethnicity ${ }^{a}$} \\
\hline Hispanic & 205.1 & $17.6 \%$ & $21.1 \%$ & 1.25 \\
\hline Not-Hispanic & 163.5 & $82.4 \%$ & $78.9 \%$ & 0.80 \\
\hline \multicolumn{5}{|l|}{ By race ${ }^{a}$} \\
\hline White & 110.6 & $73.0 \%$ & $47.3 \%$ & 0.33 \\
\hline African American & 551.6 & $12.7 \%$ & $40.9 \%$ & 4.77 \\
\hline Asian & 38.2 & $5.4 \%$ & $1.2 \%$ & 0.21 \\
\hline Native American/Alaska Native & 637.3 & $0.8 \%$ & $3.1 \%$ & 3.82 \\
\hline Pacific Islander & 1269.2 & $0.2 \%$ & $1.3 \%$ & 7.52 \\
\hline Multiple race & 341.8 & $3.1 \%$ & $6.3 \%$ & 2.07 \\
\hline \multicolumn{5}{|l|}{ By household type ${ }^{a}$} \\
\hline Households with children $<18$ & 135.8 & $43.2 \%$ & $34.3 \%$ & 0.69 \\
\hline Anyone else & 197.4 & $56.8 \%$ & $65.7 \%$ & 1.45 \\
\hline \multicolumn{5}{|l|}{ By age: ${ }^{\mathrm{a}}$} \\
\hline$<18$ & 155.0 & $22.9 \%$ & $20.8 \%$ & 0.88 \\
\hline $18-24$ & 170.5 & $9.7 \%$ & $9.7 \%$ & 1.00 \\
\hline$>24$ & 176.2 & $67.4 \%$ & $69.5 \%$ & 1.10 \\
\hline \multicolumn{5}{|l|}{ Special populations } \\
\hline Veteran (among those aged $18+)^{\mathrm{a}}$ & 210.8 & $5.9 \%$ & $7.3 \%$ & 1.25 \\
\hline $\begin{array}{l}\text { Severely mentally ill (among those } \\
\text { aged } 18+)^{b}\end{array}$ & 1055.2 & $3.3 \%$ & $20.3 \%$ & 7.86 \\
\hline Chronic substance abuse (among aged & & & & \\
\hline $18+)^{\mathrm{c}}$ & 459.9 & $5.9 \%$ & $16.0 \%$ & 3.08 \\
\hline HIV positive ${ }^{d}$ & 4019.3 & $0.3 \%$ & $7.3 \%$ & 25.30 \\
\hline Victims of domestic violence $\mathrm{e}^{\mathrm{e}}$ & 496.3 & $5.5 \%$ & $15.8 \%$ & 3.26 \\
\hline \multicolumn{5}{|l|}{ By $\mathrm{CoC}^{\mathrm{f}}$} \\
\hline CoCs in top 10 metro areas & 333.8 & $16.9 \%$ & $33.6 \%$ & 2.49 \\
\hline CoCs in metro areas $11-25$ & 222.0 & $8.7 \%$ & $11.5 \%$ & 1.36 \\
\hline Other CoCs in metro areas & 137.1 & $49.8 \%$ & $40.7 \%$ & 0.69 \\
\hline Non-metro area/rest of state CoCs & 96.9 & $24.6 \%$ & $12.2 \%$ & 0.51 \\
\hline
\end{tabular}

For the dummy variable Homeless and a demographic variable $\mathrm{x}$ that is also a dummy variable, the risk ratio is defined as $\operatorname{Pr}($ Homeless $=1 \mid x=1) / \operatorname{Pr}($ Homeless $=1 \mid x=0)$.

a Population breakdowns are from the 2013-2017 ACS.

b https://www.nimh.nih.gov/health/statistics/mental-illness.shtml

c https://www.samhsa.gov/data/sites/default/files/cbhsqreports/NSDUHDetailedTabs2017/NSDUHDetailedTabs2017.htm\#tab5-1A

d https://www.cdc.gov/hiv/pdf/library/reports/surveillance/cdc-hiv-surveillance-report-2017-vol-29.pdf

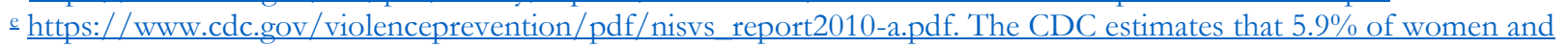
$5.0 \%$ of men have experienced domestic violence, rape, or stalking in the past 12 months.

fMapping of counties into CoCs are from Evans et al. (2019). 
Table 2:

Comparison of PIT and NCES Homeless Numbers

\begin{tabular}{ccc}
\hline \hline & $2014 / 15$ & 2015 \\
& NCES Data & PIT Data \\
Category & Enrolled & Children \\
& Students & Under 18 \\
\hline Homeless by PIT estimate & 219,629 & 122,013 \\
& $(436.5)$ & $(174.4)$ \\
Sheltered & 180,302 & 111,692 \\
Unsheltered & $(358.4)$ & $(159.7)$ \\
& 39,327 & 10,321 \\
Non PIT Categories & $(78.2)$ & $(14.8)$ \\
& & \\
Doubled-up & $1,039,240$ & \\
& $(2065.6)$ & \\
Motel/hotels/transitional & 957,053 & \\
& $(1902.2)$ & \\
& 82,187 & \\
Total & $(163.4)$ & \\
& & \\
\hline \hline
\end{tabular}

Numbers in parentheses are rates per 100,000 in the group. 